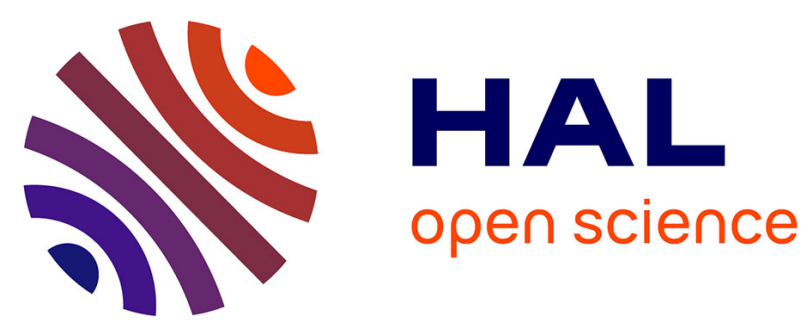

\title{
Small freshwater ecosystems with dissimilar microbial communities exhibit similar temporal patterns
}

Gwendoline David, Purificación López-garcía, David Moreira, Benjamin Alric, Philippe Deschamps, Paola Bertolino, Gwendal Restoux, Emma Rochelle-newall, Marianne Simon, Ludwig Jardillier

\section{To cite this version:}

Gwendoline David, Purificación López-garcía, David Moreira, Benjamin Alric, Philippe Deschamps, et al.. Small freshwater ecosystems with dissimilar microbial communities exhibit similar temporal patterns. Molecular Ecology, 2021, 30 (9), pp.2162-2177. 10.1111/mec.15864 . hal-03327969

\section{HAL Id: hal-03327969 \\ https://hal.science/hal-03327969}

Submitted on 20 Oct 2021

HAL is a multi-disciplinary open access archive for the deposit and dissemination of scientific research documents, whether they are published or not. The documents may come from teaching and research institutions in France or abroad, or from public or private research centers.
L'archive ouverte pluridisciplinaire HAL, est destinée au dépôt et à la diffusion de documents scientifiques de niveau recherche, publiés ou non, émanant des établissements d'enseignement et de recherche français ou étrangers, des laboratoires publics ou privés. 
3 Gwendoline M. David ${ }^{1}$, Purificación López-García ${ }^{1}$, David Moreira¹, Benjamin Alric ${ }^{2}$,

4 Philippe Deschamps ${ }^{1}$, Paola Bertolino ${ }^{1}$, Gwendal Restoux $^{3}$, Emma Rochelle-Newall ${ }^{4}$, $5 \quad$ Elisa Thébault ${ }^{4}$, Marianne Simon $^{1}$ and Ludwig Jardillier ${ }^{1}$

7 'Université Paris-Saclay, CNRS, AgroParisTech, Ecologie Systématique Evolution, 891405 , Orsay, France

9 2Irstea, UR RiverLy, Laboratoire d'écotoxicologie, centre de Lyon-Villeurbanne, 5 rue 10 de la Doua CS 20244, F-69625, Villeurbanne, France

${ }^{3} \mathrm{GABI}$, INRA, AgroParisTech, Universite Paris-Saclay, 78350 Jouy-en-Josas, France ${ }^{4}$ Sorbonne Université, UPEC, CNRS, IRD, INRAE, Institute d'Ecologie de des Sciences de l'Environnement de Paris, iEES-Paris, F-75005 Paris, France

*For correspondance: E-mail: ludwig.jardillier@universite-paris-saclay.fr, Tel. +33 169157989

Running title: Microbial dynamic in shallow freshwater systems Keywords: freshwater / microbial eukaryotes / prokaryotes / plankton / dynamics 
Despite small freshwater ecosystems are biodiversity reservoirs and significantly contribute to greenhouse fluxes, their microbial communities remain largely understudied. Yet, microorganisms intervene in biogeochemical cycling and impact water quality. Because of their small size, these ecosystems are in principle more sensitive to disturbances, seasonal variation and pluri-annual climate change. However, how microbial community composition varies over space and time, and whether prokaryotic and eukaryotic communities behave similarly, remain fully open questions. Here, we aim at unravelling the composition and intra/inter-annual temporal dynamic patterns for both prokaryotes and microbial eukaryotes in a set of small freshwater ecosystems. We monitored prokaryote composition during 24 consecutive months in four ponds and one brook from North-Western France by 165 rDNA amplicon sequencing (microbial eukaryotes were previously investigated for the same systems). Unexpectedly for oxic environments, bacterial Candidate Phyla Radiation (CPR) were highly diverse and locally abundant. Our results suggest that microbial community structure is mainly driven by environmental conditions acting over space (ecosystems) and time (seasons). A low proportion of OTUs $(<1 \%)$ was shared by the five ecosystems despite their geographical proximity, making microbial communities almost unique in each ecosystem and highlighting the strong selective influence of local environmental conditions. Marked and similar seasonality patterns were observed for prokaryotes and microbial eukaryotes in all ecosystems despite strong turnovers of rare OTUs. Over the two-year survey, microbial community composition varied despite relatively stable environmental parameters. This suggests that biotic associations play an important role in inter-annual community assembly. 


\section{Introduction}

Small freshwater ecosystems such as ponds or shallow lakes remain largely unexplored, despite being widespread and numerically very important $\left(3.2 \times 10^{9}\right.$ natural ponds on Earth of $0.0001-0.001 \mathrm{~km}^{2}$ in size) and, covering altogether a large area $\left(0.8\right.$ billion $\mathrm{km}^{2}$ ) (Downing, 2010). Collectively, they contribute up to $15 \%$ of $\mathrm{CO}_{2}$ and, especially, 40\% of $\mathrm{CH}_{4}$ emissions (Holgerson \& Raymond, 2016; Yvon-Durocher, Hulatt, Woodward, \& Trimmer, 2017). They exhibit highly diverse physicochemical conditions and are reservoirs of an important biodiversity in terms of small invertebrates and microorganisms as identified by classical observation (Dudgeon et al., 2006) and a few molecular diversity studies (e.g. Liu et al., 2020; Qin et al., 2016; Simon et al., 2014, 2015). Because of their small volume, small aquatic ecosystems have lower buffering capacity toward environmental variation at short i.e. seasons and longer, multiple-year time scales. Consequently, their communities and functioning are in principle more reactive to environmental changes than those of larger ecosystems (Downing, 2010; Downing et al., 2006; McKee et al., 2003). Understanding the temporal dynamics of organisms inhabiting these overlooked ecosystems is one of a first step to understand and predict their functioning in the long run.

Indeed, because their fundamental roles in ecosystem functioning (Azam et al., 1983; Bar-On, Phillips, \& Milo, 2018; Cho \& Azam, 1988), changes in microbial community composition can have profound impacts on ecosystem processes due to changes in their functional capacities (Bell, Newman, Silverman, Turner, \& Lilley, 2005). However, most studies of microbial communities in freshwater systems have focused on their composition and spatial distribution (Debroas et al., 2017; Grossmann et al., 2016; Richards \& Bass, 2005; Richards et al., 2015; Shade, Gregory 
71 Caporaso, Handelsman, Knight, \& Fierer, 2013; Zhong et al., 2016; Zwirglmaier et

al., 2008). Temporal surveys in aquatic systems have been only occasionally carried out, mostly at relatively short scales (days to months) (Bunse \& Pinhassi, 2017; Fuhrman, Cram, \& Needham, 2015; Scherer et al., 2017). However, longer-term studies eventually reflecting seasonal patterns are still very rare (Gilbert et al., 2012; Karl \& Church, 2014; Linz et al., 2017). Furthermore, most microbial diversity studies, including temporal surveys, focus on either prokaryotic or eukaryotic communities, but an integrated view of how the two change with time, eventually revealing underlying biotic interactions, are extremely scarce and restricted to large environments such as oceans and lakes (Biller et al., 2018; Obertegger, Pindo, \& Flaim, 2019; Steele et al., 2011). Yet, differences in overall metabolic capabilities, physiology, trophic features, generation time and dispersal might reflect in distinct temporal patterns of prokaryotes (bacteria, archaea) versus microbial eukaryotes. For instance, microbial eukaryotes have much more restricted metabolic capabilities compared to prokaryotes that have widely diverse energy and carbon metabolisms. In contrast, many microbial eukaryotes are predators, including some microalgae (Bjorbækmo, Evenstad, Røsæg, Krabberød, \& Logares, 2020; Sherr \& Sherr, 1994; Zubkov \& Tarran, 2008), while predation is exceptional in prokaryotes (Shiratori, Suzuki, Kakizawa, \& Ishida, 2019).

Here, we investigate the bacterial and archaeal community composition during 24 consecutive months in four shallow ponds and one brook located in the natural regional park of the Haute Vallée de Chevreuse (France) using 16S rDNA amplicon sequencing. We subsequently compare the temporal patterns of prokaryotic communities to those of microbial eukaryotes previously analyzed for the same ecosystems (Simon, Jardillier, et al., 2015), analyzing them as a function of several 
environmental parameters using diverse metrics and multivariate statistical analyses. Although the five ecosystems harbour specific microbial communities, their temporal patterns were similar. Interestingly, both the prokaryotic and eukaryotic communities also show similar inter-annual temporal dynamics.

\section{Material and methods}

\section{Sampling and measurement of physicochemical parameters}

We sampled monthly at the deepest site surface waters from five representative small and shallow freshwater ecosystems (the four ponds Etang des Vallées (EV), La Claye (LC), Mare Gabard (MG), Saint Robert (SR), and the brook Ru Sainte Anne (RSA)), previously described (Simon et al., 2014), between April 2011 and April 2013 (24 sampling dates) using sterilized plastic carboys. A total of 106 samples were collected (LC and RSA dried out occasionally). Single samples were analysed at each time point of this study since our protocol ensured very similar replicates (Simon et al., 2014). The five ecosystems are located in the Natural Regional Park of the Chevreuse Valley (Ile-de-France, France), less than $10 \mathrm{~km}$ apart. During our two-year survey, the Ru Sainte Anne and La Claye experienced several dry periods, from August to September 2012 for Ru Sainte Anne, and from July to December 2011 and in September 2012 for La Claye. These five ecosystems differ in their environmental conditions (Simon, López-García, et al., 2015). Water temperature $(\mathrm{T})$, dissolved oxygen concentration $\left(\mathrm{O}_{2}\right), \mathrm{pH}$ and conductivity (Cond) were measured in situ using a multiparameter probe Multi 350i (WTW, Weilheim, Germany). Concentrations of dissolved nutrients (total phosphorus ( $\left.P_{\text {tot }}\right)$, orthophosphate $\left(\mathrm{PO}_{4}^{3-}\right)$, total nitrogen $\left(\mathrm{N}_{\text {tot }}\right)$, nitrite $\left(\mathrm{NO}_{2}^{-}\right)$, nitrate $\left(\mathrm{NO}_{3}{ }^{-}\right)$and ammonia $\left(\mathrm{NH}_{3}\right)$ ) were measured on the sampling day using colorimetric tests 
120 following manufacturer instructions (Hach-Lange, Düsseldorf, Germany). Samples

121 filtered onto $0.2 \mu \mathrm{m}$ pore-size Nuclepore membranes (Whatman) were immediately

122 frozen at $-20^{\circ} \mathrm{C}$ until measurement (Rochelle-Newall, Hulot, Janeau, \& Merroune,

123 2014) of dissolved organic carbon (DOC) using a TOC VCSH analyzer (Shimadzu,

124 Tokyo, Japan). Water samples were transported back to the laboratory and

125 immediately serially filtered through $100,30,5$ and $0.2-\mu \mathrm{m}$ pore-size Nuclepore

126 filters (Whatman). Filters were immediately stored frozen at $-80^{\circ} \mathrm{C}$ until DNA

127 extraction.

DNA extraction, amplification and sequencing of 165 and 185 rDNA fragments DNA was extracted from cells collected in the smallest size-fraction $(0.2-5$

$131 \mu \mathrm{m})$ using the PowerSoil DNA extraction kit (Qiagen, Hilden, Germany) as previously

132 described (Simon et al. 2014). 16S rDNA fragments of ca. $290 \mathrm{bp}$, encompassing the

133 V4 hypervariable region, were PCR-amplified using the universal primers U515F (5'-

134 GTGCCAGCMGCCGCGGTAA-3') and 806R (5'-GGACTACVSGGGTATCTAAT-3') targeting

135 both bacteria and archaea (Baker, Smith, \& Cowan, 2003; Takai, Horikoshi, \& Takai,

136 2000). These primers were tagged with different 10 bp Molecular IDentifiers (MIDs)

137 to allow differentiation of PCR products from 20 distinct samples pooled together for

138 multiplex sequencing. PCR amplification was conducted in a total volume of $25 \mu \mathrm{l}$

139 using $1.5 \mathrm{mM} \mathrm{MgCl} 2,0.2 \mathrm{mM}$ dNTPs, $0.3 \mu \mathrm{M}$ primers, $0.3-3 \mu \mathrm{l}$ of DNA sample and 0.5

140 U HotStart Taq polymerase (Taq Platinum, Invitrogen, Carlsbad, CA, USA). Twenty-

141 five amplification cycles $\left(94^{\circ} \mathrm{C}\right.$ for $30 \mathrm{~s}, 58^{\circ} \mathrm{C}$ for $45 \mathrm{~s}$ and $72^{\circ} \mathrm{C}$ for $90 \mathrm{~s}$ ) were

142 preceded by a 3-min denaturation step at $94^{\circ} \mathrm{C}$ and ended by a $10-\mathrm{min}$ for final

143 extension at $72^{\circ} \mathrm{C}$. The products of five PCR reactions were pooled together for each 
144 sample. These pools were then purified with the QIAquick PCR purification kit

145 (Qiagen, Hilden, Germany). Equivalent amounts of purified amplicons of 20 different 146 samples were pooled and pyrosequenced using the 454 GS-FLX Titanium technology

147 from Roche (Beckman Coulter Genomics, Danvers, MA, USA). In the case of

148 eukaryotes, 18S rDNA fragments of ca. $550 \mathrm{bp}$, encompassing the V4 hypervariable

149 region, were PCR amplified (Simon et al., 2014) with primers EK-565F and 18S-EUK-

150 1134-R-UnonMet (5'-TTTAAGTTTCAGCCTTGCG-5') biased against Metazoa (Bower et

151 al., 2004).

152

\section{Analysis of $\mathbf{1 6 S}$ and 185 rDNA 454-pyrosequences}

154 A total of 1705835165 rDNA amplicon reads was obtained. Reads were filtered

155 through an in-house pipeline to remove spurious sequences. Briefly, pyrosequences

156 without the two flanking primer sequences or containing errors in primer/MIDs

157 sequences or positions with undetermined bases were discarded. To further

158 eliminate PCR and pyrosequencing errors, pairwise flowgram alignments were

159 clustered and treated with the PyroNoise program of AmpliconNoise (Quince, 160 Lanzen, Davenport, \& Turnbaugh, 2011). Filtered reads were then clustered into

161 Operational Taxonomic Units (OTUs) with a 97\% similarity cut-off (Stackebrandt \&

162 Goebel, 1994) using CD-hit (Fu, Niu, Zhu, Wu, \& Li, 2012) and SWARM (Mahé, Rognes,

163 Quince, de Vargas, \& Dunthorn, 2015). Singletons (OTUs composed of only one single 164 sequence) were excluded. Each OTU was represented by its most abundant 165 sequence, used as reference. Reference sequences were assigned to taxonomic 166 groups using 'vsearch' (Rognes et al., 2016), based on similarity with sequences of

167 the SILVA 128 database (http://www.arb-silva.de). Reads affiliated to mitochondria 168 and chloroplast were excluded from the dataset. At the end, 1131900 high-quality 
reads were retained and assigned to 16573 (CD-HIT) and 32802 (SWARM) OTUs.

170 Sequences from all OTUs were then attributed to samples according to their MIDs.

171 OTU sequences of 0.2-5 $\mu \mathrm{m}$ microbial eukaryotes were obtained following a similar

172 procedure to that followed for 18S rDNA amplicons (Simon, López-García, et al.,

173 2015). The number of OTUs affiliated to microbial eukaryotes was 3742 (CD-HIT) and

1749278 (SWARM). Sequencing data for the last four months of the temporal series in

175 Mare Gabard could unfortunately not be generated. Prokaryotic sequences have been

176 deposited at GenBank under Bioproject number PRJNA539931.

\section{Statistical analyses}

179 All statistical analyses were conducted with the R software (http://cran.rproject.org) (R Development Core Team 2019). Missing physico-chemical values (13\% of the physico-chemical dataset) were replaced by the overall average value of the parameter and nutrient concentrations below kit detection limits (19\% of the physico-chemical dataset) were set as the limit value minus a small random number

184 (normal distribution $\mu=0 ; \sigma=10^{-6}$ ) for all statistical analyses. To take into account the measured environmental factors altogether in the diverse statistical analyses, their values were normalized $(\mu=0, \sigma=1)$. OTU datasets based on CD-hit and SWARM yielded similar statistical analysis results. For clarity, we therefore discuss only

188 results based on CD-hit sequence clustering. Relative OTU abundances were obtained

189 by dividing the number of reads for each OTU by the total number of reads retrieved 190 in the sample. OTUs were divided into two groups based on their relative abundance

191 and temporal frequencies as in Simon et al. (2015): abundant OTUs, with a mean 192 relative abundance superior to $0.1 \%$ and detected in at least $25 \%$ of the samples 193 within one ecosystem, and rare OTUs, represented by all the remaining OTUs. All 
194 subsequent statistical analyses based on Bray-Curtis dissimilarities (Bray \& Curtis,

195 1957) were conducted on Wisconsin-standardized OTU relative frequencies to

196 balance the weight between abundant OTUs and rare OTUs. For global microbial

197 community analyses, i.e. considering eukaryotic and prokaryotic datasets together,

198 tables of Wisconsin-standardized OTU frequencies were pooled into a single table

199 without changing the initial relative OTU frequencies.

200 In each ecosystem, richness, evenness and diversity index were calculated. Richness

201 was evaluated by rarefaction analyses as the estimated number of OTUs in a random

202 subsample of each sequence library, which is of the same size as the smallest one

203 (Hurlbert, 1971). Evenness, e, was calculated according to Pielou (1966): $e=$

$204 \frac{-\sum_{i} p_{i} \times \ln \left(p_{i}\right)}{\ln (S)}$ with $\mathrm{p}_{\mathrm{i}}$ the frequency of OTU and $\mathrm{S}$ the observed number of OTUs in the

205 sample. Diversity was estimated according to the Gini-Simpson index (Gini, 1912;

206 Lee, Buckley, Etienne, \& Lear, 2013; Simpson, 1949) calculated as follows using the

207 'diversity' function of the 'vegan' R-package (Oksanen et al., 2018): $S=1-$ $208 \sum_{i} p_{i}^{2}$

209 Microbial community structuring was investigated in the different ecosystems. We

210 drawn Venn diagrams to show shared OTUs between ecosystems, using the 'gplots'

211 R-package (Warnes et al., 2015). Hierarchical cluster analysis was build using Bray-

212 Curtis dissimilarities and the Ward2 algorithm (Murtagh \& Legendre, 2014) in the

213 'hclust' function of the 'stats' R-package to determine clusters of microbial

214 communities based on the distances between every samples of the five ecosystems.

215 Patterns in the temporal dynamics of prokaryotes and eukaryotes were explored at

216 intra- (seasons) and inter-annual (between years) scales. Pairwise Bray-Curtis

217 dissimilarities were computed between samples collected the first year and samples 
218 from the same system the second year over increasing time-lags (from one-month to

219 12-months) to characterize the temporal dynamics of microbial communities at the

220 year-scale. Time-lag analyses (TLA, Collins, Micheli, \& Hartt, 2000) between

221 sampling dates over increasing time-lags (from one-month to 23-months) were

222 computed using Bray-Curtis dissimilarities for microbial communities and Euclidean

223 distances for environmental parameters to determine their variability over

224 consecutive years. We computed polynomial regressions (fitting better than

225 sinusoidal regressions) of Bray-Curtis dissimilarities over time to estimate the

226 frequency of any putative temporal cyclic pattern and linear regressions over time

227 to estimate global shifts in the microbial community compositions and environmental

228 parameters over the two-year survey using the ' $\mathrm{Im}$ ' function of the 'stats' R-package.

229 The best fitted polynomial model was determined based on the Akaike Information

230 Criterion (AIC, Akaike, 1973). In TLA, the slope of the linear regression indicates the

231 rate and direction of temporal changes. To test for the significance of slopes for

232 each ecosystem, a randomization procedure was applied with 5000 permutations

233 using the 'Imperm' function of the 'ImPerm' R-package (Wheeler \& Torchiano, 2016).

234 A null distribution was estimated from each slope that was calculated on randomized

235 data. The observed slopes were then compared to the distribution of F-values

236 obtained under the null hypothesis. OTU turnovers were calculated between seasons

237 or between years of the two-year survey, using the 'codyn' R-package based on the

238 following formula (Diamond, 1969; Hallett et al., 2016; MacArthur \& Wilson, 1963):

239 Turnover $=\frac{\text { Speciesgained }+ \text { Specieslost }}{\text { TotalSpeciesobservedinbothtimepoints }}$. Canonical correspondence

240 analyses were conducted to determine the contribution of each environmental factor

241 to the variation of microbial community composition. 
242 Microbial community assembly was investigated considering the potential interplay

243 between habitats (i.e. ecosystems) and time. To assess how close are microbial

244 community compositions between sampling sites or seasons, non-metric

245 multidimensional scaling (NMDS) analyses were performed based on Bray-Curtis

246 dissimilarities using the 'vegan' R-package. To quantify the role played by the

247 ecosystem clusters (i.e. groups of ecosystems defined in the hierarchical cluster

248 analysis), the habitat (i.e. ecosystems), the time (i.e. year of sampling or the

249 sampling season) in the structuring of the microbial communities, we conducted

250 permutational multivariate analyses of variance (PERMANOVA) using Bray-Curtis

251 dissimilarities calculated on OTU relative frequencies using the 'adonis' function of

252 the 'vegan' R-package.

253 We explored biotic interactions by inferring how prokaryotes and microbial

254 eukaryotes may influence each other assembly over time in each ecosystem. To do

255 so, putative multicollinearity between environmental parameters was checked by

256 computing the variance inflation factors (VIF) with the function vif.cca of the 'vegan'

257 R-package. A VIF value above 10 indicated a strong multicollinearity. Environmental

258 factors were excluded from the analysis if they were characterized by

259 multicollinearity. Forward selection was then used to sort environmental parameters

260 explaining significantly community composition variation for CCA model (Monte Carlo

261 permutation tests, 999 permutations). The synchrony of microbial eukaryotes and

262 prokaryotes was assessed using the correlation between multivariate vectors (RV

263 index) that represents the variability explained by the two communities. This index

264 was calculated using co-inertia analysis based on 999 permutations (Dolédec \&

265 Chessel, 1994). CCA combined to forward selection were conducted to determine

266 how prokaryotes explain the variance of microbial eukaryotes and inversely. 
Results

269 We generated prokaryotic 16S rDNA amplicon data (Supplementary Table S1) for

270 plankton samples (106 samples; 0.2-5 $\mu \mathrm{m}$ size-fraction) collected monthly for two

271 years from five shallow freshwater ecosystems for which protist communities had

272 been previously studied (Simon, López-García, et al., 2015). These spatially close

273 ecosystems varied in their physico-chemical conditions. The main differences were

274 lower $\mathrm{pH}$ (6.2 on average) and nitrite concentrations $\left(0.0086 \mathrm{mg} \mathrm{l}^{-1}\right.$ on average) in

275 Mare Gabard, lower ammonia concentrations $\left(0.07 \mathrm{mg} \mathrm{l}^{-1}\right.$ on average) in La Claye,

276 variable ammonia inputs $\left(<0.1\right.$ to $\left.2.65 \mathrm{mg} \mathrm{l}^{-1}\right)$ in Saint Robert, higher oxygen (79.2\%

277 on average) and lower orthophosphate $\left(0.05 \mathrm{mg} \mathrm{l}^{-1}\right)$ concentrations in Etang des

278 Vallées, and higher conductivity $\left(657.3 \mu \mathrm{S} \mathrm{cm}^{-1}\right)$ in the stream Ru Sainte Anne. All

279 the ecosystems were characterized by strong temporal variations in water

280 temperature (thermal amplitude of $19.4^{\circ} \mathrm{C} \pm 2.3$ on average, for the five ecosystems)

281 whereas the other environmental parameters had no apparent temporal variability

282 (Simon, López-García, et al., 2015).

\section{Prokaryotic community composition}

From the total number of retained high-quality $16 \mathrm{~S}$ rRNA gene reads ( 1131

285900 ), we determined a total of 16573 prokaryotic OTUs (14 701 bacterial and 1872

286 archaeal). The total number of OTUs in the Ru Sainte Anne brook was higher than in

287 the four ponds, where similar amounts of OTUs were detected (Figure 1A), an

288 observation consistent with that of eukaryotic diversity (Simon, López-García, et al.,

289 2015). Consequently, richness, evenness and diversity (Simpson index) were similar

290 in the four ponds and reached higher values (mean richness of 546, Simpson index of 
0.99 and evenness of 0.85 ) in the Ru Sainte Anne (Figure 1B). The spread of the

292 quartiles of the box plots suggested that these indices varied strongly over time and

293 differently among ecosystems (Figure 1B). Overall, only 271 OTUs (considering only

294 one occurrence for OTUs detected in several ecosystems; $1.6 \%$ of all OTUs) were

295 abundant (i.e. detected in each ecosystem in at least $25 \%$ of samples and with $\geq 0.1 \%$

296 relative abundance per sample) but represented $84.0 \%$ of the total number of reads

297 (Supplementary Table S2). The vast majority of the prokaryotic diversity was thus

298 composed of rare OTUs (Supplementary Figure S1A and S1B).

Prokaryotic OTUs affiliated to 78 different phyla, which we classified into 8

300 super-groups of different taxonomic levels: Archaea (not further subdivided in taxa

301 owing to their lower relative diversity and abundance in our samples), Fibrobacteres-

302 Chlorobi-Bacteroidetes (FCB), Microgenomates, Parcubacteria, Proteobacteria,

303 Planctomycetes-Verrucomicrobia-Chlamydiae (PVC), Terrabacteria and Other

304 Bacteria (Figure 1C). The highest number of phyla (71 against 64 on average for the

305 other ecosystems) was found in Ru Sainte Anne. Bacteria clearly dominated (98.0\%

306 of all reads) the prokaryotic community in the five ecosystems. Archaea were

307 globally rare at the exception of Ru Sainte Anne, where they reached their higher

308 abundances (8.1\% of all reads). Woesearchaeota prevailed within Archaea (1.7\% of

309 all reads), whereas Bacteria were dominated in the five ecosystems by four phyla:

310 Proteobacteria (on average, $34.1 \%$ of reads; including, by decreasing frequency

311 order, Beta-, Gamma-, Alpha-, Delta- and Epsilonproteobacteria with respectively

$31223.4,5.24,3.87,0.97,0.60 \%$ of the reads on average), Actinobacteria $(20.0 \%)$,

313 Bacteroidetes (19.3\%), and Verrucomicrobia (9.0\%). Although Proteobacteria was the

314 most abundant phylum in all ecosystems, the other phyla contributed differently to

315 the structure of the prokaryotic communities in the five ecosystems (Supplementary 
316 Figure S1C). The bacterial Candidate Phyla Radiation (CPR) was represented in our

317 samples by 27 phyla that accounted for $9.9 \%$ of all reads. They corresponded mainly

318 to the super-phyla Parcubacteria (67.2\% of CPR-affiliated reads), Microgenomates

$319(8.5 \%)$ and to the phyla Gracilibacteria $(8.1 \%)$. In contrast with its relatively small

320 frequency in the ponds, Parcubacteria was the most abundant group in Ru Sainte

321 Anne (28.4\% of all reads).

322 The five ecosystems harboured very diverse prokaryotic communities at the

323 OTU level. Only 152 (CD-hit) and 91 (SWARM) OTUs were shared by all the ecosystems

324 (Figure 2A and Supplementary Figure 2A). Although they represented less than 1\% of

325 all OTUs, they contributed to $61.0 \%$ of all reads in the five ecosystems. Shared OTUs

326 were affiliated to 23 bacterial phyla and only to 2 archaeal phyla (Woesearchaeota

327 and Methanobacteria). Abundant OTUs represented 59.9\% of the shared OTUs and

328 belonged to the most frequent phyla (i.e. Proteobacteria, Bacteroidetes,

329 Actinobacteria, Verrucomicrobia). Among the rest of shared OTUs, i.e. the rare ones,

330 Archaea were prominent along with Parcubacteria, Proteobacteria and

331 Bacteroidetes. Prokaryotic communities were mainly composed of shared OTUs in La

332 Claye (5.2\% OTUs and $80.8 \%$ reads) and non-shared ones in Ru Sainte Anne $(98.7 \%$

333 OTUs and $68.4 \%$ reads). We used NMDS analysis based on OTU frequencies (CD-hit

334 and SWARM based clustering) to highlight the dissimilarities between the prokaryotic

335 communities of the five ecosystems (Figure 2B and Supplementary Figure 2B). These

336 communities seemed to be more similar in Etang des Vallées and Saint Robert, where

337 Proteobacteria, Actinobacteria, Bacteroidetes and Verrucomicrobia were the most

338 abundant phyla (Supplementary Figure S3). Mare Gabard harboured the highest

339 abundance of Proteobacteria, which represented more than half of the prokaryotic

340 community in this ecosystem (56\% of all reads, divided mostly between 
341 betaproteobacteria and gammaproteobacteria with represented respectively 37.6

342 and $14.5 \%$ of the reads). Ru Sainte Anne had a more homogenous prokaryotic 343 community structure at the phylum level and hosted the highest proportions of 344 Azambacteria and Woesearchaeota.

345 The temporal dynamics of the prokaryotic phyla was characterized by small 346 changes at the month scale in the five ecosystems (Supplementary Figure S3). The 347 highest abundances of Archaea were recorded in Ru Saint Anne in November 2011 348 (29.1\% of all reads), July 2012 (25.2\%) and, to a lower extent, in November 2012 349 (18.6\%) and December 2012 (20.9\%), and were mainly driven by Woesearchaeota 350 (Supplementary Figure S4). Proteobacteria, Actinobacteria and Bacteroidetes 351 showed very different temporal dynamics between ecosystems. Proteobacteria 352 reached their highest abundances in June 2012 in Mare Gabard $(81.8 \%$ of all reads, 353 including gamma- and betaproteobacteria with respectively 45.7 and $34.1 \%$ ) and 354 Saint Robert (60.4\%, mostly represented by betaproteobacteria with $50.8 \%$ ) and in 355 October 2011 in $\mathrm{Ru}$ Sainte Anne (49.8\%, mostly represented by epsilon- and 356 betaproteobacteria with respectively 21.1 and $18.0 \%)$. Actinobacteria peaked in 357 Etang des Vallées in March 2013 (50.3\%) and at similar levels in June and November 3582012 in La Claye (46.7\% and 45.0\%, respectively). The highest abundances of 359 Bacteroidetes were recorded in Saint Robert in March 2013 (63.7\%) and in January 3602012 in Saint Robert and La Claye (54.4\% and 46.6\%, respectively). Bacteria belonging 361 to the CPR varied also greatly over time and between ecosystems. They dominated 362 in June 2011 and June 2012 (62.9\% and 63.5\%, respectively) in Ru Sainte Anne and 363 represented up to $25.2 \%$ of reads in October 2012 in La Claye. Parcubacteria and 364 Microgenomates exhibited similar temporal patterns. By contrast, Cyanobacteria 
365 were low abundant in the five ecosystems all along our survey, even in summer,

366 representing on average $0.7 \%$ of all reads.

367 Comparison of eukaryotic and prokaryotic community structures

368 After analyzing prokaryotic diversity alone, we incorporated data of the small (0.2-

$3695 \mu \mathrm{m}$ ) eukaryotes present in the same samples (Simon, López-García, et al., 2015).

370 NMDS analysis of pooled prokaryotic and eukaryotic OTU frequencies revealed

371 marked differences in microbial community composition among the five ecosystems

372 (Supplementary Figure S5). Hierarchical clustering analysis based on Bray-Curtis

373 dissimilarities of OTU frequencies supported these differences between the

374 ecosystems. As in the case of the prokaryotic community, the Ru Sainte Anne global

375 microbial community was set apart of the cluster composed of the four ponds

376 (Supplementary Figure S6). Interestingly, the cluster of Ru Sainte Anne samples also

377 contained a sample collected in La Claye just after a drought event (LC37, October 378 2012).

379 To determine the effect of the environment on the microbial community 380 composition, we conducted CCA on either prokaryotic or eukaryotic OTUs and the 381 significant physico-chemical parameters sorted out by a forward analysis.

382 Conductivity, water temperature, concentrations of nitrite and dissolved oxygen 383 were the only parameters that had a significant effect on the microbial communities 384 (10.0 and 6.9\% of variance for prokaryotes and eukaryotes, respectively) (Figure 3). 385 In addition, the influence of nitrate concentration appeared to be significant only 386 for prokaryotes. Conductivity, a proxy of the total ion concentration, explained a 387 third of the variance of prokaryotes and microbial eukaryotes on average. The 388 remaining four significant abiotic factors contributed similarly to explain the 
community structure. To further explore how the environment controls the most

390 abundant microbial taxa, we carried out CCA between various physicochemical 391 parameters and the most abundant OTUs (Supplementary Figure S7). Prokaryotes and

392 microbial eukaryotes in Etang des Vallées were highly related to $\mathrm{pH}$, concentrations

393 of dissolved oxygen, nitrite and nitrate. In Ru Sainte Anne, microbial communities

394 appeared to be only linked to conductivity. There was no apparent correlation

395 between the measured environmental parameters and the abundant prokaryotes and 396 microbial eukaryotes in the other ecosystems. To assess putative biotic interactions 397 between prokaryotes and microbial eukaryotes, we computed the RV index. 398 Considering all communities in the five ecosystems together, co-inertia analysis 399 shown that the dynamics of prokaryote and protist communities were highly and 400 significantly similar with $\mathrm{RV}=0.745(\mathrm{p}=0.001)$, suggesting co-variations as a result 401 of similar environmental triggers or biotic interactions between the two 402 communities. At the ecosystem level, a significant temporal co-variation of microbial 403 communities was observed only in Etang des Vallées and Saint Robert (Supplementary 404 Table S3). CCA analysis based on OTUs grouped by phyla showed that eukaryotes 405 explained as much as $38.6 \%$ of the variance of the prokaryotic community, mainly by 406 four eukaryotic phyla (Cryptomycota, Oomyceta, Marine Stramenopiles, 407 Chrysophyta) for which the co-inertia was significant. Inversely, five prokaryotic 408 phyla explained 21.2\% of the eukaryotic variance (Proteobacteria including beta-, 409 gamma- and epsilonproteobacteria, Actinobacteria, Bacteroidetes, Amesbacteria 410 and Woesebacteria).

411 A PERMANOVA analysis was used to quantify the role played by habitat (i.e. 412 ecosystem) and time (season and year) in the microbial community structuring at the 413 OTU level. Habitat and time had similar influences on the composition of the global 
414 microbial, prokaryotic and eukaryotic communities. Differences in the global

415 microbial communities between the Ru Sainte Anne and the other ecosystems were

416 greater (F.model value of 4.739) than between these four remaining ecosystems

417 (F.model value of 2.9607) (Table 1). To a lower extent, microbial communities

418 shifted over time at seasonal and year scales ( $F$.model values of 1.4079 and 1.2424,

419 respectively). Similar results were obtained when considering OTUs defined with the

420 SWARM clustering method (Supplementary Table 4).

421 Intra- and inter-annual dynamics of abiotic parameters and microbial

422 community composition

423 We conducted time-lag analyses based on linear and polynomial regressions of 424 Bray-Curtis distances over time on environmental factors and microbial community 425 composition to assess the temporal patterns at intra- and inter-annual scales. The 426 slopes of the linear regressions of abiotic parameters were either not significant 427 (Etang des Vallées, La Claye and Saint Robert) or only slightly marked (Mare Gabard 428 and Ru Sainte Anne, linear regression slopes of 0.025 and 0.036 , respectively) (Figure 4294 and Supplementary Table S5). By contrast, those for prokaryotes, microbial 430 eukaryotes and all microbes considered together were characterized by significant 431 and positive linear regressions. All the slopes were stronger for the microbial 432 communities than for the abiotic parameters (from 0.091 for La Claye to 0.192 for 433 Mare Gabard). These results suggest no or weak temporal evolution of abiotic 434 parameters when microbial communities diverged increasingly over time. These 435 effects were visible and significant even when considering similar numbers of 436 pairwise Bray-Curtis dissimilarity comparisons for all time-lag periods (data not 437 shown). The model that best fitted the distribution of the time-lag analyses for 438 prokaryotes, eukaryotes and physico-chemical parameters was a fifth order 
polynomial regression that revealed marked changes in dissimilarities at a 6-month

440 frequency. The SWARM-based dataset yielded similar results, at the exception of the

441 linear regression slopes of microbial eukaryotic communities that presented lower

442 values (Supplementary table 6). This analysis revealed significant seasonal patterns

443 for microbial communities and the environmental conditions in the five ecosystems.

444 The dispersion of the data was better explained for the biotic than for the abiotic 445 factors.

446 Pairwise Bray-Curtis dissimilarities calculated on rare and abundant OTU 447 frequencies between the two years of sampling revealed seasonality for prokaryotes, 448 microbial eukaryotes and both considered together. Globally, the temporal dynamics 449 of the abundant OTUs was characterized by seasonality, with higher dissimilarities 450 for samples separated by 5 to 6 months (i.e. opposite seasons, 0.79 average Bray451 Curtis dissimilarity) than for temporally contiguous samples (consecutive months, 4520.62 average Bray-Curtis dissimilarity) (Figure 5). Rare OTUs showed, to a lower 453 extent, similar patterns (average Bray-Curtis dissimilarity of 0.94 and 0.86 for 454 opposite seasons and consecutive months, respectively). The seasonality of abundant 455 OTUs was most pronounced in La Claye whereas there was no difference in the 456 seasonality of rare OTUs among the five ecosystems. NMDS analysis based on OTU 457 frequencies highlighted that the strongest shifts in community composition occurred 458 between winter and summer (Supplementary Figure S8), in agreement with previous 459 similar observation for microbial eukaryotes (Simon et al., 2015). Turnover values 460 for the abundant prokaryotic and eukaryotic OTUs were more marked between years $461 \quad(19.6$ and $31.4 \%$ on average, respectively) than between seasons (10.9 and $22.7 \%$ on 462 average, respectively). Turnover indices calculated for each couple of seasons were 463 higher between summer and winter, at the exception of La Claye. Rare OTUs, both 
464 prokaryotic and eukaryotic ones, were characterized by higher OTU turnover 465 between seasons and between years than abundant OTUs (Supplementary Figure S9).

\section{Discussion}

Local environmental selection drives different community compositions in

\section{small freshwater ecosystems}

In order to study the diversity and temporal dynamics of planktonic

microorganisms (0.2-5 $\mu \mathrm{m}$ size-fraction) of the three domains of life in small

472 freshwater systems, we generated $16 \mathrm{~S}$ rDNA amplicon sequences for samples

473 collected over 24 months from 4 ponds and one brook for which we previously

474 generated 185 rDNA datasets from the same original samples (Simon, López-García, 475 et al., 2015). These systems were characterized by differences in their physico476 chemical conditions (Simon, López-García, et al., 2015). Ru Sainte Anne and La Claye 477 experienced drought events that lasted up to five months. We retrieved a total 478 number of 16573 OTUs affiliated to prokaryotes (14 701 bacterial OTUs and 1872 479 archaeal OTUs) for a total of 3583 OTUs affiliated to microbial eukaryotes. These 480 numbers are higher than those usually retrieved in other freshwater ecosystems 481 (Bock, Salcher, Jensen, Pandey, \& Boenigk, 2018; Llirós et al., 2014) even after our 482 very stringent analysis of the sequence data (see Methods; Supplementary Table S1 483 and S2). The higher diversity actually reflects the cumulative effect of observed 484 OTUs along time series and highlights the importance of integrating temporal scales 485 to better depict global microbial biodiversity (Simon, López-García, et al., 2015). 486 Not surprisingly, microbial communities were mainly composed of rare OTUs 487 (Supplementary Table 2), for both prokaryotes and microbial eukaryotes. Rare OTUs 
488 were affiliated to all the 78 detected prokaryotic phyla whereas abundant OTUs $489 \quad(\geq 0.1 \%)$ were restricted to 32 phyla.

490 Most prokaryotic phyla were widespread in the five ecosystems; only a few low491 abundant ones were not detected in all of them. On average, the prokaryotic OTU 492 richness was about five times higher than that of eukaryotes at each sampling date 493 (Figure 1B), which is in agreement with the global higher diversity of prokaryotes 494 (e.g. Hug et al., 2016). Proteobacteria (mostly alpha-, beta- and 495 gammaproteobacteria), Bacteroidetes, Actinobacteria and Verrucomicrobia 496 dominated (Supplementary Figure S1), as often observed in freshwater lentic 497 ecosystems (Newton, Jones, Eiler, McMahon, \& Bertilsson, 2011; Riemann et al., 498 2008; Zwart, Crump, Kamst-van Agterveld, Hagen, \& Han, 2002). Cyanobacteria were 499 detected at low abundances, likely because we focused on the small size-fraction $500(0.2-5 \mu \mathrm{m})$ whereas freshwater Cyanobacteria are usually of larger size or 501 filamentous. CPR bacteria and the Diapherotrites-Parvarchaeota-Aenigmarchaeota502 Nanoarchaeota-Nanohaloarchaeota (DPANN) supergroups, which have few cultured 503 representatives and are likely composed of symbionts (Castelle et al., 2018), were 504 observed in the five ecosystems. In particular, Woesearchaeota was the most 505 abundant archaeal phylum (X. Liu et al., 2018) (Figure 1C, Supplementary Figure S4).

506 Despite these overall similarities and despite high OTU turnover rates at intra507 and inter-annual scales (Supplementary Figure S9), each ecosystem harboured 508 specific prokaryotic communities mainly composed of non-shared OTUs (Figure 2 and 509 Supplementary Figure S6) as observed in other freshwater environments, including 510 lakes (Bock et al., 2018; Linz et al., 2017). Each of the five ecosystems appears to 511 represent a specific habitat for diverse prokaryotic communities because of 512 particular physico-chemical conditions, nutrient composition, availability as 
513 previously described for these ecosystems (Simon, López-García, et al., 2015), and

514 for other freshwater environments (Fisher, Klug, Lauster, Newton, \& Triplett, 2000;

515 Peura et al., 2012). In clear contrast with the four ponds analyzed, the prokaryotic

516 community in the Ru Sainte Anne brook was very different. This lotic ecosystem

517 harboured a prokaryotic community that was characterized by the highest richness

518 and evenness as well as by the highest abundances of Archaea and CPR bacteria

519 (Figure 1A-C and 2B, Supplementary Figure S6). This higher richness might be related

520 to a higher input on allochthonous microbes (e.g. from soil or upstream waters) into

521 the system (e.g. Crump, Amaral-Zettler, \& Kling, 2012; Teachey, McDonald, \&

522 Ottesen, 2019).

523 In addition to this major difference in community composition between the brook

524 and the four ponds, we also observed differences among all the five small freshwater

525 ecosystems (Figure 2, Supplementary Figure S5 and S6) despite their spatial

526 proximity. These differences may be the result of a combination of diverse ecological

527 processes (Goldford et al., 2018) that can explain the high OTU turnover rates

528 observed (Supplementary Figure S9). Many microbes exhibit a high dispersion

529 capacity promoted by natural vectors such as wind, rain, and animals (birds and

530 mammals). However, the capacity to colonize a new environment faces diverse biotic

531 and abiotic filters (e.g. competition, chemistry of the ecosystem, hydrology). Among

532 these factors, competition between autochthonous and dispersing microbes is known

533 to be crucial to limit successful immigration (Comte, Berga, Severin, Logue, \&

534 Lindström, 2017; Logue \& Lindström, 2010). In this regard, we detected 62.7 and

$53539.6 \%$ of prokaryotic and eukaryotic OTUs, respectively, that occurred only once in

536 all ecosystems over the two-year survey. In addition to their very sporadic

537 occurrence, the abundance of these OTUs was very low, with less than 15 reads on 
538 average. These OTUs likely represent dispersing cells that did not succeed to colonize

539 our ecosystems and were no longer detected at subsequent dates. However, this was

540 not the case for all rare OTUs, since some of them reached high abundances

541 punctually. For instance, a rare OTU affiliated to Firmicutes accounted for 2403

542 (30.2\%) reads in La Claye in July 2012. We can hypothesize that these rare OTUs

543 come from a local seed bank and may bloom when very particular environmental

544 conditions occur. The fact that two of our ecosystems (La Claye and Ru Sainte Anne)

545 experienced drought events that lasted 1 to 5 months and that, each time, microbial

546 communities recovered their original structure within a month after water refill

547 (Supplementary Figure S3) also strongly advocates for the existence of seed banks in

548 these ecosystems for both the abundant and part of the rare OTUs (Shade et al.,

549 2012; Simon et al., 2016).

\section{Prokaryotes and microbial eukaryotes share similar temporal patterns}

Our multivariate statistical analyses showed that the microbial community 552 composition in the five freshwater ecosystems was not only driven by the particular 553 environmental conditions of each system but also by their temporal variations at

554 different time scales (Table 1). Microbial communities can exhibit non-seasonal 555 dynamics due to marked and fast shifts in environmental conditions. These shifts can 556 easily take place in small freshwater ecosystems because their shallow depths and 557 small volumes make them sensitive to local and short-time scale climate variations 558 (Bock et al., 2018; Downing, 2010; Simon, López-García, et al., 2015). In fact, even

559 if rapid changes can occur in larger ecosystems such as lakes (Mangot et al., 2013), 560 climate has usually a lower impact at short-time scales on lakes and oceans, where 561 microbial seasonal successions are well documented (Fuhrman et al., 2015; Tammert 562 et al., 2015). Nevertheless, despite punctual marked shifts in environmental 
563 conditions, we observed global seasonal patterns in both the environmental

564 parameters (Figure 4), and the prokaryotic and eukaryotic microbial communities

565 (Table 1 and Supplementary Table S5, Figures 4-5 and Supplementary Figure S8).

566 These communities were more differentiated at summer and winter, possibly

567 because of higher OTU turnover rates occurring at these two opposed seasons.

568 Concomitantly, communities also experienced composition changes at a monthly

569 scale, more pronounced for rare taxa than for abundant taxa (Supplementary Figure

570 S9). Interestingly, at a much longer time scale, we also observed constant directional

571 shift (increasing dissimilarity over time) of both the prokaryotic and eukaryotic

572 communities, and the whole microbial community structures over the two-year

573 survey (Figure 4, Supplementary Table S5), a phenomenon that has already been

574 observed in larger lakes and in marine systems (Chow et al., 2013; L. Liu, Yang, Yu,

$575 \&$ Wilkinson, 2015).

576 As mentioned above, diverse simultaneous processes affecting community 577 assembly can explain this marked microbial dynamics, including immigration, the 578 presence of a seed bank, and genetic or ecological drift (Chase, 2007; Evans, Martiny, 579 \& Allison, 2016; Logares et al., 2018). The temporal community composition changes 580 observed in our ecosystems occurred in environmental conditions that were 581 relatively stable at the inter-annual scale (Figure 4). This may explain partly why 582 seasonal changes of both prokaryotes and microbial eukaryotes were slightly driven $583(<10 \%$ of variance explained) by a restricted subset of measured physico-chemical 584 parameters (temperature, total concentration of ions (conductivity), dissolved 585 oxygen and nitrate concentrations) (Figure 3 and Supplementary Figure S7). In

586 addition to possible abiotic factors not measured during this study (e.g. light quantity 587 and quality, wind, rainfall, specific hydrochemistry), biotic interactions were most 
588 likely also involved in determining the microbial community assembly as is assumed

589 for other ecosystems (Lindström \& Langenheder, 2012; Yannarell \& Triplett, 2005).

590 Many microbial eukaryotes prey on prokaryotes (Boenigk \& Arndt, 2002; Pernthaler,

591 2005). Likewise, diverse symbioses (from mutualistic to parasitic ones) are

592 established between microorganisms of the three domains of life (González-Olalla,

593 Medina-Sánchez, Lozano, Villar-Argaiz, \& Carrillo, 2018; Zehr, Shilova, Farnelid,

594 Muñoz-Maríncarmen, \& Turk-Kubo, 2016) and influencing community composition. In

595 return, the composition of prey and host communities may affect that of their

596 respective predators and symbionts (Šimek et al., 2013). Time series with adapted

597 time scale and sampling frequency are crucial to resolve these biotic interactions

598 between microorganisms (Kelly et al., 2019; Moreira \& López-García, 2019). Although

599 our monthly sampling was likely too sparse to accurately assess potential synchrony

600 between prokaryotes and microbial eukaryotes (that can often experience rapid

601 changes on daily or weekly basis), we were able to identify an overall marked

602 correlation between the changes in prokaryote community composition and those of

603 microbial eukaryotes (Supplementary Table 3). This observation supports, beyond

604 physicochemical change, the occurrence of top-down processes between

605 heterotrophic eukaryotes and prokaryotes (Massana \& Logares, 2013).

607 If predation is one of the main recognized biotic interactions at the base of 608 trophic webs, symbioses (including interactions going from parasitism to mutualism)

609 are widespread among microbial communities and can also play key roles (Harding

610 et al., 2018; Hudson, Dobson, \& Lafferty, 2006). We observed a large proportion of

611 probable symbiotic taxa among the microbial eukaryotes and prokaryotes identified

612 in our ecosystems. For example, based on the very limited biosynthetic capacities 
613 encoded in their genomes, CPR bacteria are inferred to live in symbiosis with other

614 prokaryotes (Castelle \& Banfield, 2018). Overall, in the five ecosystems, the most

615 abundant CPR phyla were Azambacteria (3.14\%), Nomurabacteria (0.92\%),

616 Gracilibacteria (0.80\%), Saccharibacteria (0.52\%) and Peregrinibacteria (0.43\%).

617 Interestingly, CPR bacteria have been found mostly in oxygen-depleted, sulfide-rich

618 environments (Castelle et al., 2018). Our sampled ecosystems are somewhat oxygen-

619 depleted but display oxic conditions on the surface. We recorded the highest

620 proportions (44.9\% of reads, $46.3 \%$ of OTUs) in Ru Sainte Anne (47.2\% [ $\mathrm{O}_{2}$ ] on average)

621 and low proportions (2.3\% of reads, $24.3 \%$ of OTUS) in Mare Saint Robert $\left(38.6 \%\left[\mathrm{O}_{2}\right]\right.$

622 on average). We cannot rule out the hypothesis that CPR bacteria were more

623 abundant in the sediments or in the suboxic deeper waters of our ecosystems, and

624 that those that we detected were cells suspended again from the bottom to the

625 surface since these ecosystems are characterized by frequent water column mixing.

626 Nevertheless, we did retrieve in our samples very low numbers of sequences from

627 anaerobic prokaryotes typical of sediments, such as methanogenic archaea $(0.14 \%$ of

628 all reads in all ecosystems) or sulfate-reducing Desulfobacteraceae $(0.068 \%)$. This

629 suggests a moderate input of cells from the sediment, so that the much larger

630 amounts of CPR bacteria that we detected most likely correspond to bona fide

631 members of the planktonic community and not cells suspended again from the

632 sediment. Nonetheless, methanogenesis and sulfate-reduction are active local

633 processes associated to the degradation of abundant organic matter (bubbling and

634 strong $\mathrm{H}_{2} \mathrm{~S}$ smell during sampling are observed in some systems, e.g. Mare Gabard, 635 especially in warmer seasons). Therefore, CPR and their hosts might be more linked

636 to sulfide availability than to the absence of dissolved oxygen per se. In addition,

637 CPR bacteria were consistently retrieved from the five ecosystems even if their 
638 presumed size (Luef et al., 2015) is below the $0.2 \mu \mathrm{m}$ pore-size of the membranes

639 that we used to collect cells. Therefore, their relative proportion might have been

640 underestimated in our study, since many cells unattached to their hosts might have

641 escaped detection. At any rate, the relatively high abundance of CPR bacteria in

642 these small water bodies opens intriguing questions about their ecological role.

643 Despite their likely dependence on other organisms, CPR bacteria exhibit a wide

644 range of metabolic activities. For example, among the CPR lineages detected in this

645 study, Microgenomates have the potential to degrade a large range of carbon

646 substrates (Danczak et al., 2017), Parcubacteria can be involved in the nitrogen cycle

647 through denitrification and Saccharibacteria (TM7) and Dojkabacteria (WS6) have

648 been reported as parasites (Castelle \& Banfield, 2018). The same situation might

649 apply to the potentially parasitic Woesearchaeota (X. Liu et al., 2018), which reach

650 relative high abundance in some of our shallow freshwater ecosystems. The

651 importance of parasitism in aquatic plankton communities is well known (Hudson et

652 al., 2006; Jephcott et al., 2016; Lafferty, Dobson, \& Kuris, 2006). In particular, since

653 parasites have complex life cycles and are known to infect organisms at various

654 trophic levels, they increase the complexity of planktonic trophic networks by

655 extending the food chains (Grami et al., 2011) and enhancing the level of biodiversity

656 (Hudson et al., 2006). This, in turn, may result in the increase of both the

657 connectivity and efficiency of carbon fluxes, although these potential consequences

658 are still subject to debate (Grami et al., 2011).

659 In summary, our study revealed a high diversity of prokaryotes in addition to that 660 previously observed for microbial eukaryotes in small freshwater ecosystems.

661 Despite a microbial community structure characterized by a predominance of rare 662 taxa and a marked OTU turnover rate, we observed marked seasonal patterns and 
663 community drift over the two-year survey for both prokaryotes and microbial 664 eukaryotes of five different microbial communities. These observations suggest that 665 diverse prokaryote and eukaryote communities react similarly to environmental

666 changes over time (seasonal to multiple-year scale). These changes were only 667 partially driven by measured environmental conditions. By contrast, biotic 668 interactions, such as symbiosis, are suspected to play more significant roles. The 669 abundance of CPR bacteria in some of these ecosystems suggests that they may be 670 important ecological players also in oxic environments.

\section{$671 \quad$ Acknowledgements}

672 We thank F. Hardy, the Parc Naturel Régional de la Haute Vallée de Chevreuse 673 and the Office National des Forêts du Parc de Rambouillet for access and information 674 about the sampling sites. This work was supported by the 'Initiative Doctorale 675 Interdisciplinaire' Program of the IDEX Paris-Saclay, the CNRS EC2CO program 676 (project 'DEPICT') and the European Research Council under the European Union's 677 Seventh Framework Program (ERC Grant Agreements 322669 'ProtistWorld' and 678787904 'Plast-Evol').

$679 \quad$ Conflict of Interest

680 The authors declare no conflict of interest. 
687

688

689

690

691

692

693

694

695

696

697

698

699

700

701

702

703

704

705

706

707

708

Akaike, H. (1973). Maximum likelihood identification of gaussian autoregressive moving average models. Biometrika, 60(2), 255-265. doi: 10.1093/biomet/60.2.255

Azam, F., Fenchel, T., Field, J., Gray, J., Meyer-Reil, L., \& Thingstad, F. (1983). The Ecological Role of Water-Column Microbes in the Sea. Marine Ecology Progress Series, 10(July 2016), 257-263. doi: 10.3354/meps010257

Baker, G. C., Smith, J. J., \& Cowan, D. A. (2003). Review and re-analysis of domain-specific 16S primers. J ournal of Microbiological Methods, 55(3), 541555. doi: 10.1016/j.mimet.2003.08.009

Bar-On, Y. M., Phillips, R., \& Milo, R. (2018). The biomass distribution on Earth. Proceedings of the National Academy of Sciences of the United States of America, 115(25), 6506-6511. doi: 10.1073/pnas.1711842115

Bell, T., Newman, J. A., Silverman, B. W., Turner, S. L., \& Lilley, A. K. (2005). The contribution of species richness and composition to bacterial services. Nature, 436(7054), 1157-1160. doi: 10.1038/nature03891

Biller, S. J., Berube, P. M., Dooley, K., Williams, M., Satinsky, B. M., Hackl, T., ... Chisholm, S. W. (2018). Data descriptor: Marine microbial metagenomes sampled across space and time. Scientific Data, 5, 1-7. doi: $10.1038 /$ sdata.2018.176

Bjorbækmo, M. F. M., Evenstad, A., Røsæg, L. L., Krabberød, A. K., \& Logares, R. (2020). The planktonic protist interactome: where do we stand after a century of research? ISME J ournal, 14(2), 544-559. doi: 10.1038/s41396-019-0542-5 
Bock, C., Salcher, M. M., Jensen, M., Pandey, R. V., \& Boenigk, J. (2018). Synchrony of Eukaryotic and Prokaryotic Planktonic Communities in three seasonally sampled Austrian Lakes. Frontiers in Microbiology, 9(June), 1290. doi: $10.3389 / F M I C B .2018 .01290$

Boenigk, J., \& Arndt, H. (2002). Bacterivory by heterotrophic flagellates: Community structure and feeding strategies. Antonie van Leeuwenhoek, International J ournal of General and Molecular Microbiology, 81(1-4), 465480. doi: 10.1023/A:1020509305868

Bower, S. M., Carnegie, R. B., Goh, B., Jones, S. R. M., Lowe, G. J., \& Mak, M. W. S. (2004). Preferential PCR amplification of parasitic protistan small subunit rDNA from metazoan tissues. J ournal of Eukaryotic Microbiology, 51(3), 325332. doi: 10.1111/j.1550-7408.2004.tb00574.x

Bray, J. R., \& Curtis, J. T. (1957). An Ordination of the Upland Forest Communities of Southern Wisconsin. Ecological Monographs, 27(4), 325-349. doi: $10.2307 / 1942268$

Bunse, C., \& Pinhassi, J. (2017). Marine Bacterioplankton Seasonal Succession Dynamics. Trends in Microbiology, 25(6), 494-505. doi: $10.1016 /$ j.tim.2016.12.013

Castelle, C. J., \& Banfield, J. F. (2018). Major New Microbial Groups Expand Diversity and Alter our Understanding of the Tree of Life. Cell, 172(6), 11811197. doi: $10.1016 /$ j.cell.2018.02.016

Castelle, C. J., Brown, C. T., Anantharaman, K., Probst, A. J., Huang, R. H., \& Banfield, J. F. (2018). Biosynthetic capacity, metabolic variety and unusual 

biology in the CPR and DPANN radiations. Nature Reviews Microbiology, 16(10), 629-645. doi: 10.1038/s41579-018-0076-2

734 Chase, J. M. (2007). Drought mediates the importance of stochastic community assembly. Proceedings of the National Academy of Sciences of the United

Cho, B. C., \& Azam, F. (1988). Major role of bacteria in biogeochemical fluxes in the Ocean's interior. Nature, Vol. 332, pp. 441-443. doi: 10.1038/332441a0

Chow, C. E. T., Sachdeva, R., Cram, J. A., Steele, J. A., Needham, D. M., Patel,

Danczak, R. E., Johnston, M. D., Kenah, C., Slattery, M., Wrighton, K. C., \& A., ... Fuhrman, J. A. (2013). Temporal variability and coherence of euphotic zone bacterial communities over a decade in the Southern California Bight. ISME J ournal , 7(12), 2259-2273. doi: 10.1038/ismej.2013.122

Collins, S. L., Micheli, F., \& Hartt, L. (2000). A method to determine rates and patterns of variability in ecological communities. Oikos, 91(2), 285-293. doi: 10.1034/j.1600-0706.2000.910209.x

Comte, J., Berga, M., Severin, I., Logue, J. B., \& Lindström, E. S. (2017). Contribution of different bacterial dispersal sources to lakes: Population and community effects in different seasons. Environmental Microbiology, 19(6), 2391-2404. doi: 10.1111/1462-2920.13749

Crump, B. C., Amaral-Zettler, L. A., \& Kling, G. W. (2012). Microbial diversity in arctic freshwaters is structured by inoculation of microbes from soils. ISME J ournal , 6, 1629-1639. doi: 10.1038/ismej.2012.9 Wilkins, M. J. (2017). Members of the Candidate Phyla Radiation are 
functionally differentiated by carbon- and nitrogen-cycling capabilities. Microbiome, 5(1), 112. doi: 10.1186/s40168-017-0331-1

757

758

759

760

761

762

763

764

765

766

767

768

769

770

771

772

773

774

775

776

777

Debroas, D., Domaizon, I., Humbert, J. F., Jardillier, L., Lepére, C., Oudart, A., \& Taib, N. (2017). Overview of freshwater microbial eukaryotes diversity: A first analysis of publicly available metabarcoding data. FEMS Microbiology Ecology, 93(4), 1-14. doi: 10.1093/femsec/fix023

Diamond, J. M. (1969). Avifaunal equilibria and species turnover rates on the channel islands of california. Proceedings of the National Academy of Sciences of the United States of America, 64(1), 57-63. doi: 10.1073/pnas.64.1.57

Dolédec, S., \& Chessel, D. (1994). Co-inertia analysis: an alternative method for studying species-environment relationships. Freshwater Biology, 31(3), 277294. doi: 10.1111/j.1365-2427.1994.tb01741.x

Downing, J. A. (2010). Emerging global role of small lakes and ponds: Little things mean a lot. Limnetica, 29(1), 9-24.

Downing, J. A., Prairie, Y. T., Cole, J. J., Duarte, C. M., Tranvik, L. J., Striegl, R. G., ... Melack, J. M. (2006). The global abundance and size distribution of lakes, ponds, and impoundments. Limnology and Oceanography, 51(5), 23882397. doi: $10.4319 /$ lo.2006.51.5.2388

Dudgeon, D., Arthington, A. H., Gessner, M. O., Kawabata, Z. I., Knowler, D. J., Lévêque, C., ... Sullivan, C. A. (2006). Freshwater biodiversity: Importance, threats, status and conservation challenges. Biological Reviews of the Cambridge Philosophical Society, 81(2), 163-182. doi:

$10.1017 / \mathrm{S} 1464793105006950$ 
778 Evans, S., Martiny, J. B. H., \& Allison, S. D. (2016). Effects of dispersal and

779 selection on stochastic assembly in microbial communities. 11(1), 176-185.

$780 \quad$ doi: $10.1038 /$ ismej. 2016.96

781 Fisher, M. M., Klug, J. L., Lauster, G., Newton, M., \& Triplett, E. W. (2000). Effects

782 of resources and trophic interactions on freshwater bacterioplankton diversity.

783 Microbial Ecology, 40(2), 125-138. doi: 10.1007/s002480000049

784 Fu, L., Niu, B., Zhu, Z., Wu, S., \& Li, W. (2012). CD-HIT: Accelerated for clustering

785 the next-generation sequencing data. Bioinformatics, 28(23), 3150-3152. doi:

$786 \quad 10.1093 /$ bioinformatics/bts565

787 Fuhrman, J. A., Cram, J. A., \& Needham, D. M. (2015). Marine microbial

788 community dynamics and their ecological interpretation. Nature Reviews

789 Microbiology, 13(3), 133-146. doi: 10.1038/nrmicro3417

790 Gilbert, J. A., Steele, J. A., Caporaso, J. G., Steinbrück, L., Reeder, J.,

791 Temperton, B., ... Field, D. (2012). Defining seasonal marine microbial

792 community dynamics. ISME J ournal, 6(2), 298-308. doi:

$793 \quad 10.1038 /$ ismej.2011.107

794 Gini, C. (1912). Variabilità e mutabilità. Rome: Libreria Eredi Virgilio Veschi (Ed.

795 Pizetti E, Salvemini, T). Rome: Libreria Eredi Virgilio Veschi.

796 Goldford, J. E., Lu, N., Bajić, D., Estrela, S., Tikhonov, M., Sanchez-Gorostiaga, A.,

797 ... Sanchez, A. (2018). Emergent simplicity in microbial community assembly.

798 Science, 361(6401), 469-474. doi: 10.1126/science.aat1168

799 González-Olalla, J. M., Medina-Sánchez, J. M., Lozano, I. L., Villar-Argaiz, M., \&

800 Carrillo, P. (2018). Climate-driven shifts in algal-bacterial interaction of high- 
mountain lakes in two years spanning a decade. Scientific Reports, 8(1), 1-12.

802 doi: $10.1038 / s 41598-018-28543-2$

803 Grami, B., Rasconi, S., Niquil, N., Jobard, M., Saint-Béat, B., \& Sime-Ngando, T.

804 (2011). Functional effects of parasites on food web properties during the 805 spring diatom bloom in lake pavin: A linear inverse modeling analysis. PLoS

$806 \quad$ ONE, 6(8). doi: 10.1371/journal.pone.0023273

807 Grossmann, L., Jensen, M., Heider, D., Jost, S., Glücksman, E., Hartikainen, H., ...

808 Boenigk, J. (2016). Protistan community analysis: Key findings of a large-scale

809 molecular sampling. ISME J ournal, 10(9), 2269-2279. doi:

$810 \quad 10.1038 /$ ismej.2016.10

811 Hallett, L. M., Jones, S. K., MacDonald, A. A. M., Jones, M. B., Flynn, D. F. B.,

812 Ripplinger, J., ... Collins, S. L. (2016). codyn: An r package of community

813 dynamics metrics. Methods in Ecology and Evolution, 7(10), 1146-1151. doi:

$814 \quad 10.1111 / 2041-210 X .12569$

815 Harding, K., Turk-Kubo, K. A., Sipler, R. E., Mills, M. M., Bronk, D. A., \& Zehr, J. P.

816 (2018). Symbiotic unicellular cyanobacteria fix nitrogen in the Arctic Ocean.

817 Proceedings of the National Academy of Sciences of the United States of

$818 \quad$ America, 115(52), 13371-13375. doi: 10.1073/pnas.1813658115

819 Holgerson, M. A., \& Raymond, P. A. (2016). Large contribution to inland water CO2

820 and CH4 emissions from very small ponds. Nature Geoscience, 9(3), 222-226.

$821 \quad$ doi: $10.1038 /$ ngeo2654

822 Hudson, P. J., Dobson, A. P., \& Lafferty, K. D. (2006). Is a healthy ecosystem one 823 that is rich in parasites? Trends in Ecology and Evolution, 21(7), 381-385. doi: 
Hug, L. A., Baker, B. J., Anantharaman, K., Brown, C. T., Probst, A. J., Castelle, C. 826 J., ... Banfield, J. F. (2016). A new view of the tree of life. Nature

827 Microbiology, 1(5), 1-6. doi: 10.1038/nmicrobiol.2016.48

828 Hurlbert, S. H. (1971). The Nonconcept of Species Diversity: A Critique and 829 Alternative Parameters. Ecology, 52(4), 577-586. doi: 10.2307/1934145

830 Jephcott, T. G., Alves-de-Souza, C., Gleason, F. H., van Ogtrop, F. F., Sime-

831 Ngando, T., Karpov, S. A., \& Guillou, L. (2016). Ecological impacts of parasitic 832 chytrids, syndiniales and perkinsids on populations of marine photosynthetic 833 dinoflagellates. Fungal Ecology, 19, 47-58. doi: 10.1016/j.funeco.2015.03.007

Karl, D. M., \& Church, M. J. (2014). Microbial oceanography and the Hawaii Ocean Time-series programme. Nature Reviews Microbiology, 12(10), 699-713. doi:

Kelly, L. W., Nelson, C. E., Haas, A. F., Naliboff, D. S., Calhoun, S., Carlson, C. A., $838 \quad$... Rohwer, F. (2019). Diel population and functional synchrony of microbial 839 communities on coral reefs. Nature Communications, 10(1). doi:

Lafferty, K. D., Dobson, A. P., \& Kuris, A. M. (2006). Parasites dominate food web links. Proceedings of the National Academy of Sciences of the United States of

844 Lee, J. E., Buckley, H. L., Etienne, R. S., \& Lear, G. (2013). Both species sorting 845 and neutral processes drive assembly of bacterial communities in aquatic microcosms. FEMS Microbiology Ecology, 86(2), 288-302. doi: 10.1111/1574- 
848 Lindström, E. S., \& Langenheder, S. (2012). Local and regional factors influencing

849 bacterial community assembly. Environmental Microbiology Reports, 4(1), 1-9.

$850 \quad$ doi: $10.1111 / \mathrm{j} .1758-2229.2011 .00257 . x$

851 Linz, A. M., Crary, B. C., Shade, A., Owens, S., Gilbert, J. A., Knight, R., \&

852 McMahon, K. D. (2017). Bacterial community composition and dynamics

853 spanning five years in freshwater bog lakes. MSphere, 2(3), e00169-17. doi:

$854 \quad 10.1128 / \mathrm{mSphere.00169-17}$

855 Liu, L., Yang, J., Yu, Z., \& Wilkinson, D. M. (2015). The biogeography of abundant

856 and rare bacterioplankton in the lakes and reservoirs of China. The ISME

857 J ournal, 9(9), 2068-2077. doi: 10.1038/ismej.2015.29

858 Liu, X., Li, M., Castelle, C. J., Probst, A. J., Zhou, Z., Pan, J., ... Gu, J. D. (2018).

859 Insights into the ecology, evolution, and metabolism of the widespread

860 Woesearchaeotal lineages. Microbiome, 6(1), 1-16. doi: 10.1186/s40168-018-

$861 \quad 0488-2$

862 Liu, Z., Iqbal, M., Zeng, Z., Lian, Y., Zheng, A., Zhao, M., ... Xie, J. (2020).

863 Comparative analysis of microbial community structure in the ponds with

864 different aquaculture model and fish by high-throughput sequencing. Microbial

865 Pathogenesis, 142(December 2019), 104101. doi:

$866 \quad 10.1016 /$ j.micpath.2020.104101

867 Llirós, M., Inceollu, Ö., García-Armisen, T., Anzil, A., Leporcq, B., Pigneur, L. M., 868 ... Servais, P. (2014). Bacterial community composition in three freshwater 869 reservoirs of different alkalinity and trophic status. PLoS ONE, 9(12), 1-27. doi: 
871 Logares, R., Tesson, S. V. M., Canbäck, B., Pontarp, M., Hedlund, K., \& Rengefors,

872 K. (2018). Contrasting prevalence of selection and drift in the community

873 structuring of bacteria and microbial eukaryotes. Environmental Microbiology,

874 20(6), 2231-2240. doi: 10.1111/1462-2920.14265

875 Logue, J. B., \& Lindström, E. S. (2010). Species sorting affects bacterioplankton

876 community composition as determined by $16 \mathrm{~S}$ rDNA and $16 \mathrm{~S}$ rRNA fingerprints.

877 ISME J ournal, 4(6), 729-738. doi: 10.1038/ismej.2009.156

878 Luef, B., Frischkorn, K. R., Wrighton, K. C., Holman, H. Y. N., Birarda, G., Thomas,

879 B. C., ... Banfield, J. F. (2015). Diverse uncultivated ultra-small bacterial cells

880 in groundwater. Nature Communications, 6(1), 1-8. doi: 10.1038/ncomms7372

881 MacArthur, R. H., \& Wilson, E. O. (1963). An equilibrium theory of insular

$882 \quad$ zoogeography. Evolution, 10(4), 373-387.

883 Mahé, F., Rognes, T., Quince, C., de Vargas, C., \& Dunthorn, M. (2015). Swarmv2:

884 Highly-scalable and high-resolution amplicon clustering. Peer] , 2015(12), 1-12.

$885 \quad$ doi: $10.7717 /$ peerj. 1420

886 Mangot, J. F., Domaizon, I., Taib, N., Marouni, N., Duffaud, E., Bronner, G., \&

887 Debroas, D. (2013). Short-term dynamics of diversity patterns: Evidence of

888 continual reassembly within lacustrine small eukaryotes. Environmental

889 Microbiology, 15(6), 1745-1758. doi: 10.1111/1462-2920.12065

890 Massana, R., \& Logares, R. (2013). Eukaryotic versus prokaryotic marine

891 picoplankton ecology. Environmental Microbiology, 15(5), 1254-1261. doi:

$892 \quad 10.1111 / 1462-2920.12043$ 
893 McKee, D., Atkinson, D., Collings, S. E., Eaton, J. W., Gill, A. B., Harvey, I., ...

894 Moss, B. (2003). Response of freshwater microcosm communities to nutrients, 895 fish, and elevated temperature during winter and summer. Limnology and

896 Oceanography, 48(2), 707-722. doi: 10.4319/lo.2003.48.2.0707

897 Moreira, D., \& López-García, P. (2019). Time series are critical to understand

898 microbial plankton diversity and ecology. Molecular Ecology, 28(5), 920-922.

899 doi: $10.1111 / \mathrm{mec} .15015$

900 Murtagh, F., \& Legendre, P. (2014). A Run Length Transformation for Discriminating

901 Between Auto Regressive Time Series. J ournal of Classification, 31, 274-295.

902 doi: $10.1007 / \mathrm{s} 00357$

903 Newton, R. J., Jones, S. E., Eiler, A., McMahon, K. D., \& Bertilsson, S. (2011). A

904 Guide to the Natural History of Freshwater Lake Bacteria. In Microbiology and

905 Molecular Biology Reviews (Vol. 75). doi: 10.1128/mmbr.00028-10

906 Obertegger, U., Pindo, M., \& Flaim, G. (2019). Multifaceted aspects of synchrony

907 between freshwater prokaryotes and protists. Molecular Ecology, 28(19), 4500-

$908 \quad$ 4512. doi: $10.1111 / \mathrm{mec} .15228$

909 Oksanen, J., Blanchet, F. G., Kindt, R., Legendre, P., Minchin, P. R., O’hara, R. B.,

$910 \quad$... Oksanen, M. J. (2018). Vegan: community ecology package. R Package

911 Version 2. 4-6. doi: 10.1093/molbev/msv334

912 Pernthaler, J. (2005). Predation on prokaryotes in the water column and its

913 ecological implications. Nature Reviews Microbiology, 3(7), 537-546. doi:

$914 \quad 10.1038 /$ nrmicro1180

915 Peura, S., Eiler, A., Hiltunen, M., Nykänen, H., Tiirola, M., \& Jones, R. I. (2012). 
Bacterial and phytoplankton responses to nutrient amendments in a Boreal

917 lake differ according to season and to taxonomic resolution. PLOS ONE, 7(6).

918 doi: $10.1371 /$ journal.pone.0038552

919 Pielou, E. C. (1966). The measurement of diversity in different types of biological

920 collections. J ournal of Theoretical Biology, 13, 131-144. doi: 10.1016/0022-

$921 \quad 5193(67) 90048-3$

922 Qin, Y., Hou, J., Deng, M., Liu, Q., Wu, C., Ji, Y., \& He, X. (2016). Bacterial

923 abundance and diversity in pond water supplied with different feeds. Scientific

924 Reports, 6(September), 1-13. doi: 10.1038/srep35232

925 Quince, C., Lanzen, A., Davenport, R. J., \& Turnbaugh, P. J. (2011). Removing

926 Noise From Pyrosequenced Amplicons. BMC Bioinformatics, 12(38), 18. doi:

$927 \quad 10.1128 / \mathrm{JVI} .02271-09$

928 Richards, T. A., \& Bass, D. (2005). Molecular screening of free-living microbial

929 eukaryotes: Diversity and distribution using a meta-analysis. Current Opinion

930 in Microbiology, 8(3), 240-252. doi: 10.1016/j.mib.2005.04.010

931 Richards, T. A., Leonard, G., Mahé, F., Del Campo, J., Romac, S., Jones, M. D. M.,

932 ... Chambouvet, A. (2015). Molecular diversity and distribution of marine fungi

933 across 130 european environmental samples. Proceedings of the Royal Society

934 B: Biological Sciences, 282(1819). doi: 10.1098/rspb.2015.2243

935 Riemann, L., Leitet, C., Pommier, T., Simu, K., Holmfeldt, K., Larsson, U., \&

936 Hagström, Å. (2008). The native bacterioplankton community in the central

937 Baltic Sea is influenced by freshwater bacterial species. Applied and

938 Environmental Microbiology, 74(2), 503-515. doi: 10.1128/AEM.01983-07 
939 Rochelle-Newall, E., Hulot, F. D., Janeau, J. L., \& Merroune, A. (2014). CDOM

940 fluorescence as a proxy of DOC concentration in natural waters: A comparison

941 of four contrasting tropical systems. Environmental Monitoring and

942 Assessment, 186(1), 589-596. doi: 10.1007/s10661-013-3401-2

943 Rognes, T., Flouri, T., Nichols, B., Quince, C., \& Mahé, F. (2016). VSEARCH: A

944 versatile open source tool for metagenomics. Peer] , 2016(10), 1-22.

$945 \quad$ https://doi.org/10.7717/peerj.2584

946 Scherer, P. I., Millard, A. D., Miller, A., Schoen, R., Raeder, U., Geist, J., \&

947 Zwirglmaier, K. (2017). Temporal dynamics of the microbial community

948 composition with a focus on toxic cyanobacteria and toxin presence during

949 harmful algal blooms in two South German lakes. Frontiers in Microbiology, 8,

$950 \quad$ 1-17. doi: $10.3389 /$ fmicb. 2017.02387

951 Shade, A., Gregory Caporaso, J., Handelsman, J., Knight, R., \& Fierer, N. (2013). A

952 meta-analysis of changes in bacterial and archaeal communities with time.

953 ISME J ournal, 7(8), 1493-1506. doi: 10.1038/ismej.2013.54

954 Shade, A., Peter, H., Allison, S. D., Baho, D. L., Berga, M., Bürgmann, H., ...

955 Handelsman, J. (2012). Fundamentals of microbial community resistance and

956 resilience. Frontiers in Microbiology, 3, 417. doi: 10.3389/fmicb.2012.00417

957 Sherr, E. B., \& Sherr, B. F. (1994). Bacterivory and herbivory: Key roles of

958 phagotrophic protists in pelagic food webs. Microbial Ecology, 28(2), 223-235.

959 doi: $10.1007 /$ BF00166812

960 Shiratori, T., Suzuki, S., Kakizawa, Y., \& Ishida, K. ichiro. (2019). Phagocytosis-like

961 cell engulfment by a planctomycete bacterium. Nature Communications, 
963 Šimek, K., Kasalický, V., Jezbera, J., Horňák, K., Nedoma, J., Hahn, M. W., ... 964 Boenigk, J. (2013). Differential freshwater flagellate community response to 965 bacterial food quality with a focus on Limnohabitans bacteria. ISME J ournal, 966 7(8), 1519-1530. doi: 10.1038/ismej.2013.57

967 Simon, M., Jardillier, L., Deschamps, P., Moreira, D., Restoux, G., Bertolino, P., \& 968 López-García, P. (2015). Complex communities of small protists and 969 unexpected occurrence of typical marine lineages in shallow freshwater 970 systems. Environmental Microbiology, 17(36), 10-27. doi: 10.1111/14622920.12591

972 Simon, M., Jardillier, L., Deschamps, P., Moreira, D., Restoux, G., Bertolino, P., \& 973 López-García, P. (2014). Complex communities of small protists and 974 unexpected occurrence of typical marine lineages in shallow freshwater 975 systems. Environmental Microbiology, 17(10), 3610-3627. doi: 10.1111/1462$976 \quad 2920.12591$

977 Simon, M., López-García, P., Deschamps, P., Moreira, D., Restoux, G., Bertolino, 978 P., \& Jardillier, L. (2015). Marked seasonality and high spatial variability of 979 protist communities in shallow freshwater systems. The ISME J ournal, 9(9), 1980 13. doi: $10.1038 /$ ismej. 2015.6

981 Simon, M., López-García, P., Deschamps, P., Restoux, G., Bertolino, P., Moreira, 982 D., \& Jardillier, L. (2016). Resilience of freshwater communities of small 983 microbial eukaryotes undergoing severe drought events. Frontiers in 984 Microbiology, 7(MAY), 1-11. doi: 10.3389/fmicb.2016.00812 
985 Simpson, E. H. (1949). Measurement of Diversity. Nature, Vol. 163, pp. 688-688.

986 doi: $10.1038 / 163688 \mathrm{a} 0$

987 Stackebrandt, E., \& Goebel, B. M. (1994). Taxonomic note: A place for DNA-DNA

988 reassociation and $16 \mathrm{~S}$ rRNA sequence analysis in the present species definition

989 in bacteriology. International J ournal of Systematic Bacteriology, 44(4), 846-

990 849. doi: $10.1099 / 00207713-44-4-846$

991 Steele, J. A., Countway, P. D., Xia, L., Vigil, P. D., Beman, J. M., Kim, D. Y., ...

992 Fuhrman, J. A. (2011). Marine bacterial, archaeal and protistan association

993 networks reveal ecological linkages. ISME J ournal, 5(9), 1414-1425. doi:

$994 \quad 10.1038 /$ ismej.2011.24

995 Takai, K., Horikoshi, K., \& Takai, K. E. N. (2000). Rapid Detection and

996 Quantification of Members of the Archaeal Community by Quantitative PCR

997 Using Fluorogenic Probes Rapid Detection and Quantification of Members of

998 the Archaeal Community by Quantitative PCR Using Fluorogenic Probes.

999 Applied and Environmental Microbiology, 66(11), 5066-5072. doi:

$1000 \quad 10.1128$ /AEM.66.11.5066-5072.2000.Updated

1001 Tammert, H., Tšertova, N., Kiprovskaja, J., Baty, F., Nõges, T., \& Kisand, V.

1002 (2015). Contrasting seasonal and interannual environmental drivers in bacterial

1003 communities within a large shallow lake: Evidence from a seven year survey.

1004 Aquatic Microbial Ecology, 75(1), 43-54. doi: 10.3354/ame01744

1005 Teachey, M. E., McDonald, J. M., \& Ottesen, E. A. (2019). Rapid and stable

1006 microbial community assembly in the headwaters of a third-order stream.

1007 Applied and Environmental Microbiology, 85(11), 1-15. doi:

$1008 \quad 10.1128 /$ AEM.00188-19 
1009 Warnes, G. R., Bolker, B., Bonebakker, L., Gentleman, R., Liaw, W. H. A., Lumley,

1010 T., ... Venables, B. (2015). gplots: Various R Programming Tools for Plotting

1011 Data. R Package Version 2.17.0. doi: 10.1111/j.0022-3646.1997.00569.x

1012 Wheeler, R. E., \& Torchiano, M. (2016). ImPerm: Permutation tests for linear

1013 models. Cran, 2-24.

1014 Yannarell, A. C., \& Triplett, E. W. (2005). Geographic and environmental sources of

1015 variation in lake bacterial community composition. Applied and Environmental

1016 Microbiology, 71(1), 227-239. doi: 10.1128/AEM.71.1.227-239.2005

1017 Yvon-Durocher, G., Hulatt, C. J., Woodward, G., \& Trimmer, M. (2017). Long-term

1018 warming amplifies shifts in the carbon cycle of experimental ponds. Nature

1019 Climate Change, 7(3), 209-213. doi: 10.1038/nclimate3229

1020 Zehr, J. P., Shilova, I. N., Farnelid, H. M., Muñoz-Maríncarmen, M. D. C., \& Turk-

1021 Kubo, K. A. (2016). Unusual marine unicellular symbiosis with the nitrogen-

1022 fixing cyanobacterium UCYN-A. Nature Microbiology, 2(December). doi:

$1023 \quad 10.1038 /$ nmicrobiol.2016.214

1024 Zhong, Z., Liu, Y., Miao, L., Wang, F., Chu, L., Wang, J., \& Liu, Z. (2016).

1025 Prokaryotic Community Structure Driven by Salinity and Ionic Concentrations in

1026 Plateau Lakes of the Tibetan Plateau. Applied and Environmental

1027 Microbiology, 82(6), 1846-1858. doi: 10.1128/AEM.03332-15.Editor

1028 Zubkov, M. V., \& Tarran, G. A. (2008). High bacterivory by the smallest

1029 phytoplankton in the North Atlantic Ocean. Nature, 455(7210), 224-226. doi:

$1030 \quad 10.1038 /$ nature07236

1031 Zwart, G., Crump, B. C., Kamst-van Agterveld, M. P., Hagen, F., \& Han, S. K. 
1032 (2002). Typical freshwater bacteria: An analysis of available 16S rRNA gene

1033 sequences from plankton of lakes and rivers. Aquatic Microbial Ecology, 28(2),

1034 141-155. doi: $10.3354 / \mathrm{ame} 028141$

1035 Zwirglmaier, K., Jardillier, L., Ostrowski, M., Mazard, S., Garczarek, L., Vaulot, D.,

1036 ... Scanlan, D. J. (2008). Global phylogeography of marine Synechococcus and

1037 Prochlorococcus reveals a distinct partitioning of lineages among oceanic

1038 biomes. Environmental Microbiology, 10(1), 147-161. doi: 10.1111/j.1462-

$1039 \quad 2920.2007 .01440 . x$

1040

1041 


\section{Data Accessibility}

1043 DNA sequences: BioSample accessions SAMN11525783 - SAMN11525888; NCBI SRA:

1044 SRR11218723 - SRR11218819.

\section{Author contribution}

1046 Gwendoline M. David, Purificación López-García, David Moreira and Ludwig Jardillier

1047 contributed substantially to the study conception, data acquisition and analysis as

1048 well as drafting the manuscript. Benjamin Alric, Philippe Deschamps, Gwendal

1049 Restoux and Elisa Thébault contributed substantially to data analysis and drafting

1050 the manuscript. Marianne Simon and Emma Rochelle-Newall contributed

1051 substantially to data acquisition and drafting the manuscript. Paola Bertolino

1052 contributed substantially to data acquisition. All authors approved the final

1053 submitted manuscript. 
1054 Table 1: Permutational multivariate analyses of variance (PERMANOVA) partitioning of the whole

1055 microbial community, prokaryotes and microbial eukaryotes, based on Bray-Curtis dissimilarities

1056 calculated using Wisconsin standardized OTU relative abundances among hierarchical-defined clusters

10571 and 2 (see Figure S6), location (ecosystem), season and year.

1058

1059

\begin{tabular}{|c|c|c|c|c|c|c|c|c|c|c|c|c|c|c|c|c|}
\hline & \multicolumn{4}{|c|}{ Cluster } & \multicolumn{4}{|c|}{ Location | Cluster } & \multicolumn{4}{|c|}{ Season } & \multicolumn{4}{|c|}{ Year } \\
\hline & Df & F. model & $r^{2}$ & P value & Df & F. model & $r^{2}$ & Pvalue & Df & F. model & $r^{2}$ & P value & Df & F. model & $r^{2}$ & P value \\
\hline $\begin{array}{l}\text { Whole } \\
\text { microbial } \\
\text { community }\end{array}$ & 1 & 4.74 & $4.1 \times 10^{-2}$ & $5.0 \times 10^{-4}$ & 3 & 2.96 & $7.7 \times 10^{-2}$ & $5.0 \times 10^{-4}$ & 3 & 1.41 & $3.6 \times 10^{-2}$ & $5.0 \times 10^{-4}$ & 1 & 1,24 & $1.1 \times 10^{-2}$ & $1.5 \times 10^{-2}$ \\
\hline Prokaryotes & 1 & 4.51 & $3.9 \times 10^{-2}$ & $5.0 \times 10^{-4}$ & 3 & 2.65 & $6.9 \times 10^{-2}$ & $5.0 \times 10^{-4}$ & 3 & 1.31 & $3.4 \times 10^{-2}$ & $5.0 \times 10^{-4}$ & 1 & 1,26 & $1.1 \times 10^{-2}$ & $9.0 \times 10^{-3}$ \\
\hline $\begin{array}{l}\text { Microbial } \\
\text { eukaryotes }\end{array}$ & 1 & 4.95 & $4.1 \times 10^{-2}$ & $5.0 \times 10^{-4}$ & 3 & 3.30 & $8.3 \times 10^{-2}$ & $5.0 \times 10^{-4}$ & 3 & 1.48 & $3.7 \times 10^{-2}$ & $5.0 \times 10^{-4}$ & 1 & 1,25 & $1.0 \times 10^{-2}$ & $1.5 \times 10^{-2}$ \\
\hline
\end{tabular}



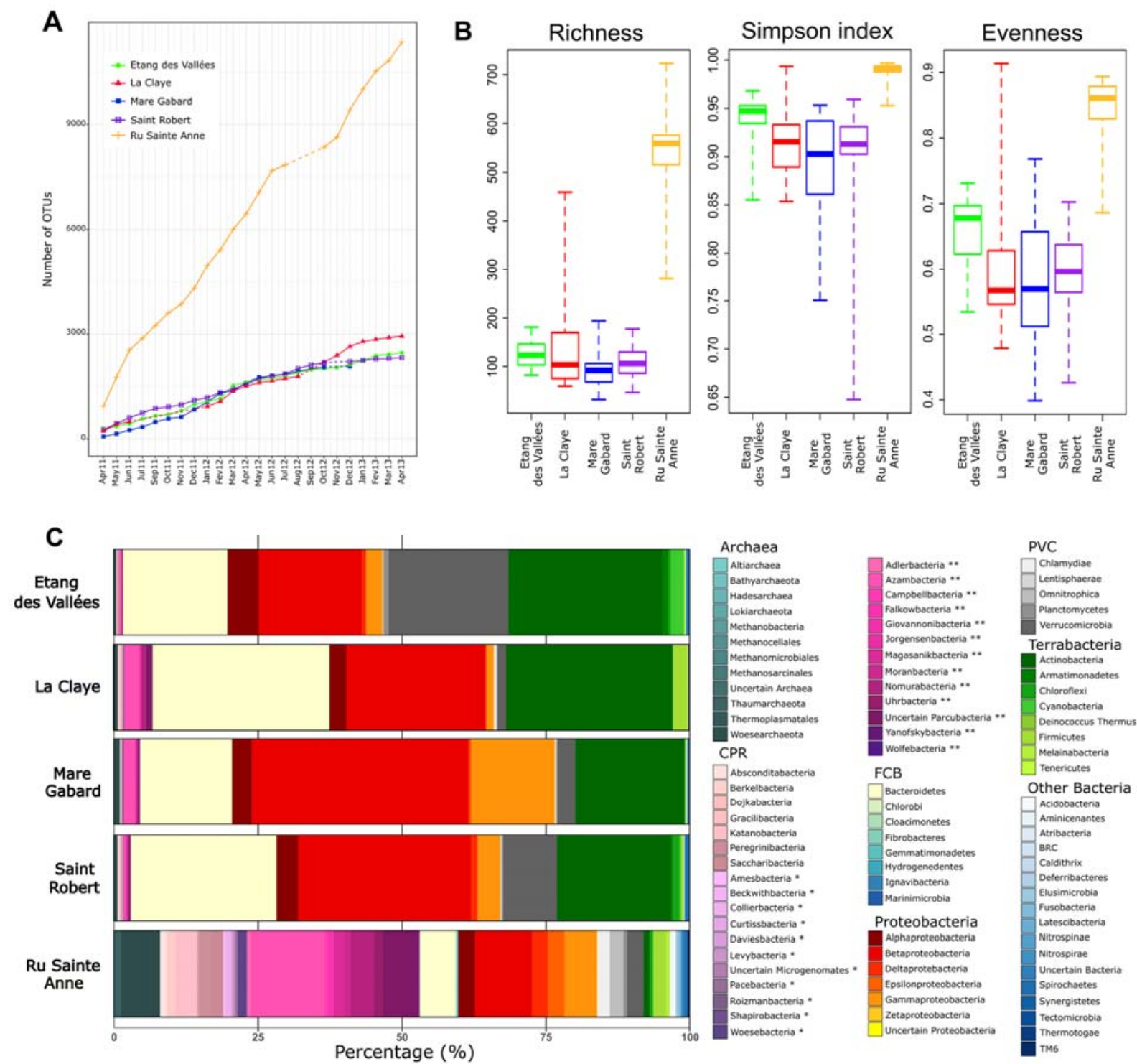

Figure 1: David et al.

Figure 1: (a) Cumulative curves showing the total number of prokaryotic OTUs detected in each

1080 des Vallées, La Claye, Mare Gabard, Saint Robert and Ru Sainte Anne). Dashed lines indicate missing

1081 data due to the drought: Ru Sainte Anne was dried in August and September 2012, and La Claye from

1082 the end of July to December 2011 and in September 2012. (b) Richness and diversity estimators

1083 computed for all the samples. Richness corresponds to the expected number of OTUs in random

1084 subsamples of the size of the smallest sequence library (1309 reads in Mare Gabard in May 2011). The

1085 thickest line inside each box represents the median on the distribution, bottom and top borders of boxes 
1086 correspond to the first and third quartiles and whiskers extend to minimal and maximal distances. (c)

1087 Histograms showing the relative abundance of $16 \mathrm{~S}$ rDNA amplicon reads assigned to high-rank taxa

1088 averaged over the two-year survey, from the five ecosystems (CPR: Candidate Phyla Radiation, FCB:

1089 Fibrobacteres-Chlorobi-Bacteroidetes, PVC: Planctomycetes-Verrucomicrobia-Chlamydiae). One star

$1090 \quad(*)$ indicates Microgenomates and two stars $(* *)$ shows Parcubacteria.

1091

1092

1093

1094

1095

1096

1097

1098

1099

1100

1101

1102

1103

1104

1105

1106

1107

1108

1109

1110

1111 

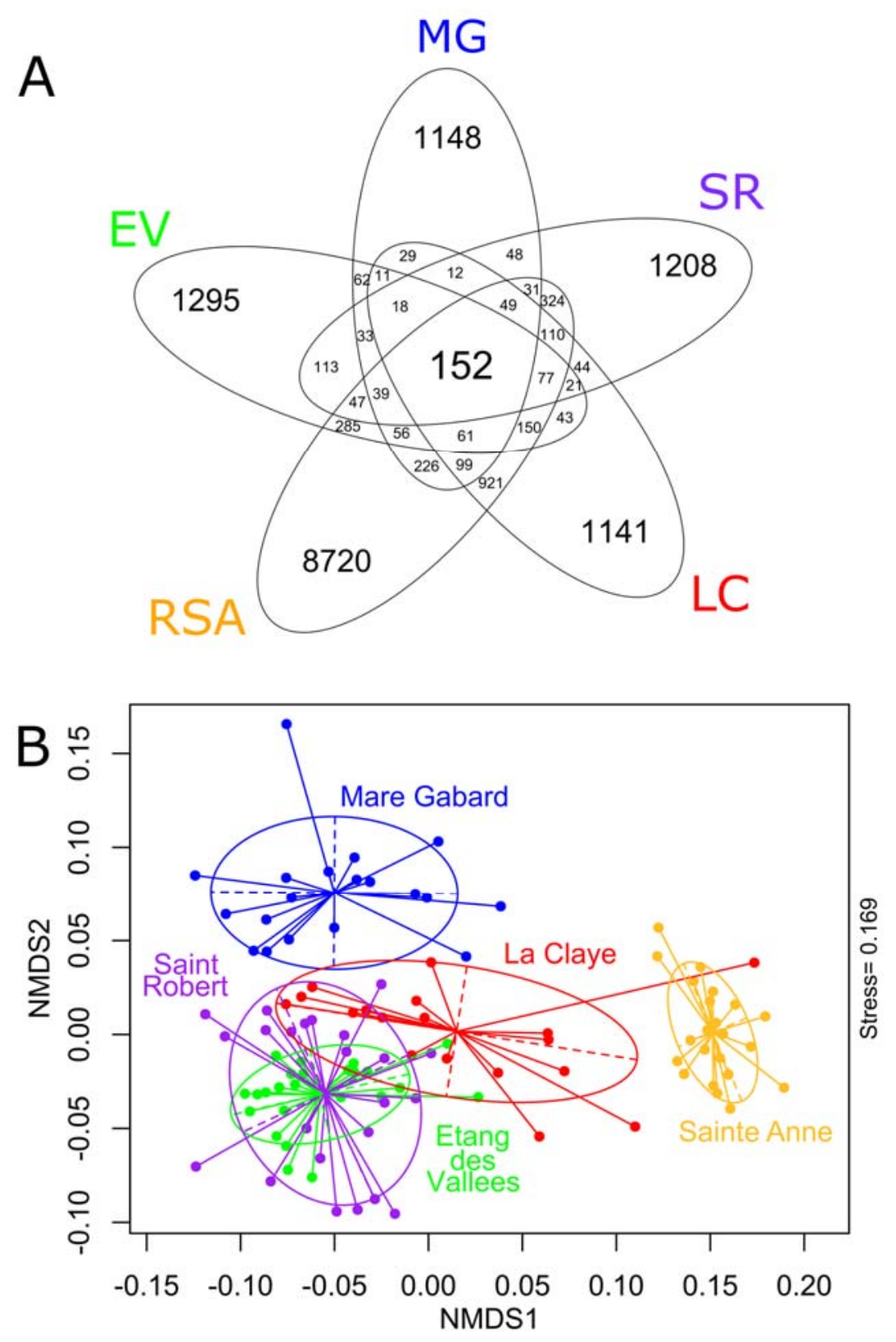

1112

Figure 2: David et al.

1118 an ecosystem. All samples from the two-year survey are pooled for each ecosystem. (b) Non-metric

1119 multidimensional scaling plot, built on Wisconsin-standardized Bray-Curtis dissimilarities between all 1120 samples. Stress value is displayed on the right border of the plot. 


\section{Microbial eukaryotes}

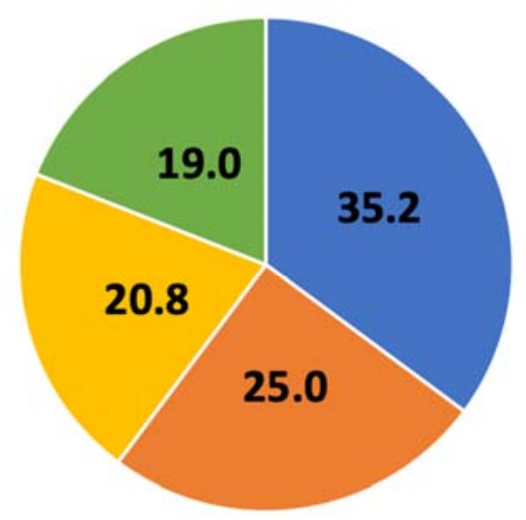

Dissolved Oxygen
Conductivity
Prokaryotes

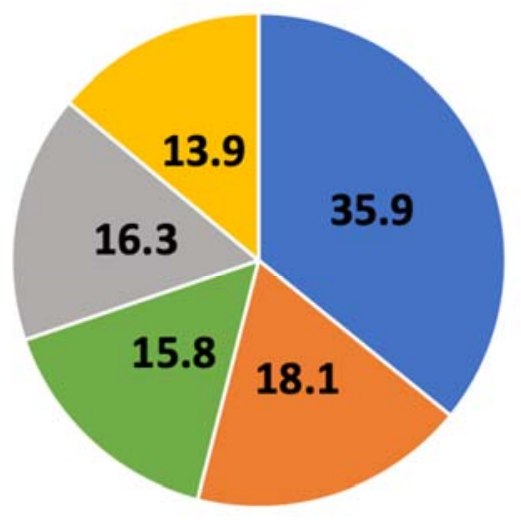

$\mathrm{NO}_{3}$
$\mathrm{NO}_{2}$

\section{Temperature}

1123

1124

1125

1126

1127

1128

1129

1130

1131

1132

1133

1134

1135

1136

1137

1138

1139

Figure 3: David et al.

Figure 3: Canonical correspondence analyses conducted on all OTUs affiliated either to microbial eukaryotes or prokaryotes retrieved in the five ecosystems over the two-year survey. OTU proportion were Wisconsin standardized. Among all measured physico-chemical parameters, only conductivity, temperature, concentrations of dissolved oxygen nitrate and nitrite were explained significantly the variance of the OTUs $(P<0.05)$. Considered together, these abiotic parameters explained 6.95 and $9.98 \%$ of the global variance of the OTUs belonging to microbial eukaryotes and prokaryotes, respectively. Values within each section of the pie charts indicate the proportion of variance explained by each parameter of the global variance of the OTUs. 


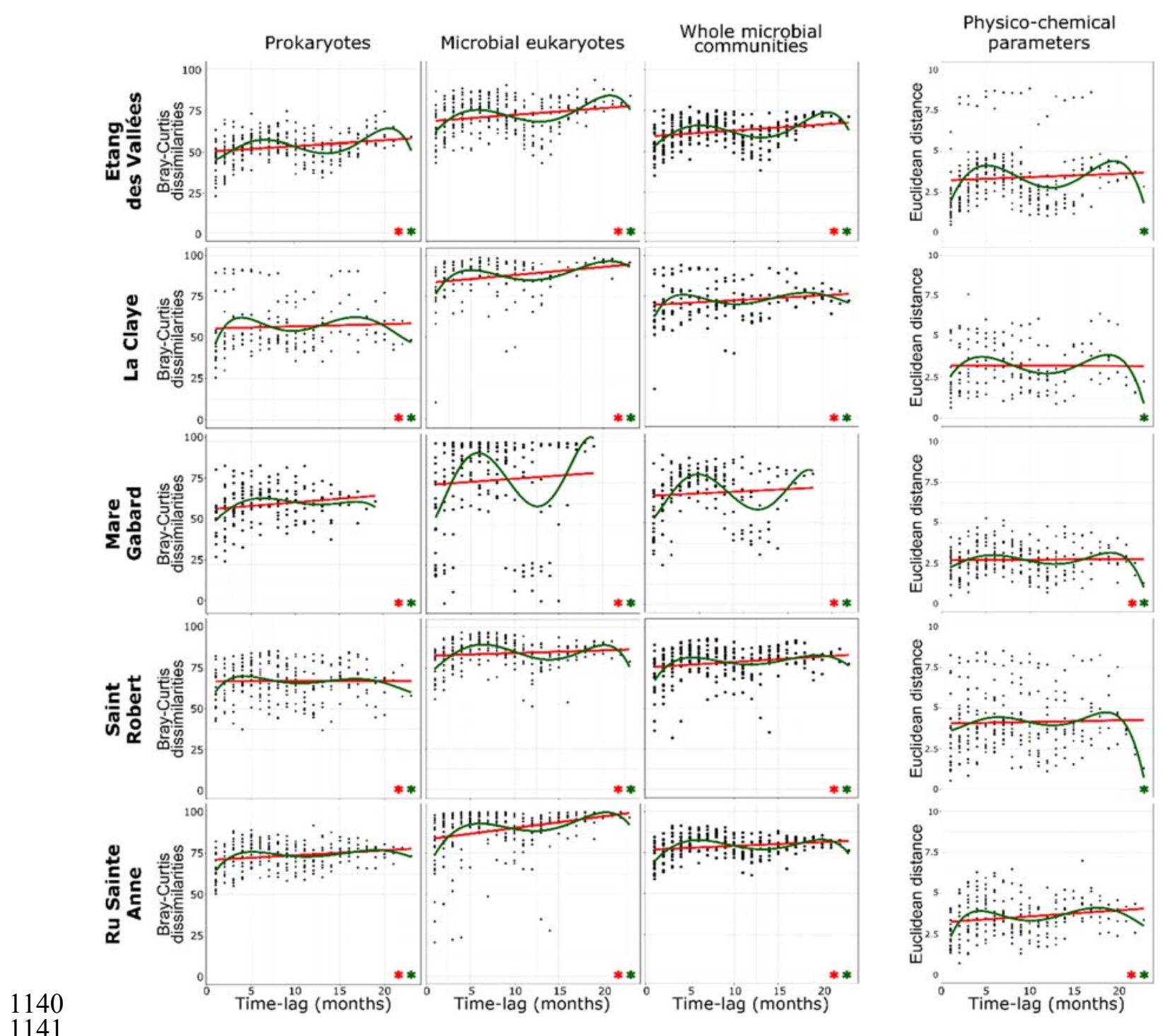

Figure 4: David et al.

Figure 4: Time-lag analyses (TLA) were computed for each ecosystem between sampling dates over

1147 increasing time-lags over the two-year survey (from one-month to 23-months). Wisconsin standardized

1148 Bray-Curtis dissimilarities were used with all OTUs of prokaryotes, microbial eukaryotes and whole

1149 microbial communities while Euclidean distances were applied with environmental parameters. Linear

1150 regressions, in red, and polynomial regressions of the 5th order, in green were calculated for each TLA

1151 dataset. Significant regressions $(P<0.05)$ are indicated with a green star (linear regressions) or a red star

1152 (polynomial regressions).

1153 


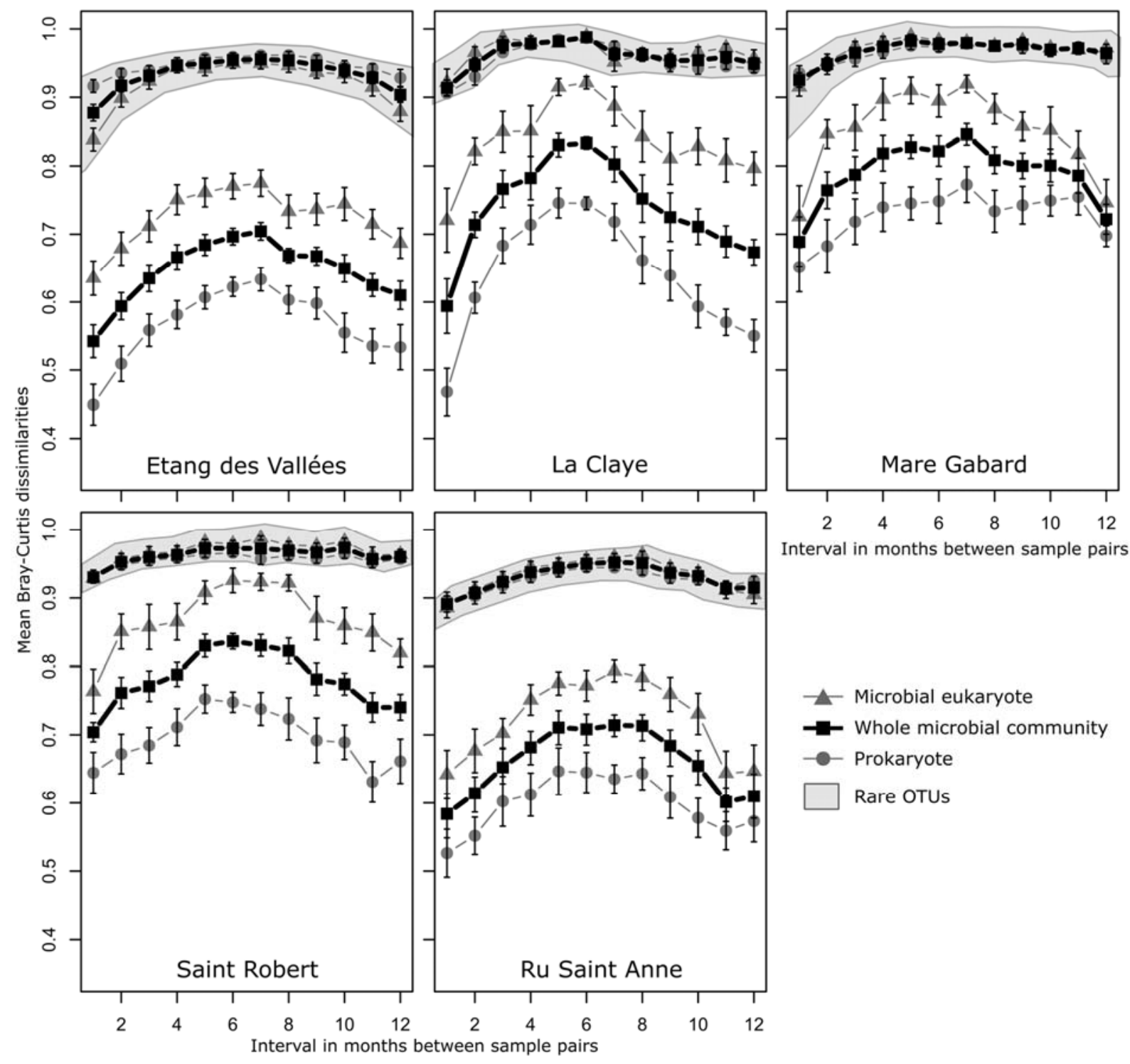

Figure 5: David et al.

Figure 5: Wisconsin standardized pairwise Bray-Curtis dissimilarities were calculated between samples

1158 separated from 1 to 12 months for abundant (detected in each ecosystem in at least $25 \%$ of samples, and 1159 with $>0.1 \%$ mean relative abundance per sample ) and rare OTUs (detected in each ecosystem in less 1160 than $25 \%$ of samples, and with $\leq 0.1 \%$ mean relative abundance per sample; curves highlighted with a 1161 grey shade) belonging to microbial eukaryotes (triangles), prokaryotes (circles) and whole microbial 1162 community (squares) detected in the five ecosystems over the two-year survey. Each point represents 1163 mean value of pairwise Bray-Curtis dissimilarities and is plotted with standard errors. 